\title{
The Landfall and Inland Penetration of a Flood-Producing Atmospheric River in Arizona. Part II: Sensitivity of Modeled Precipitation to Terrain Height and Atmospheric River Orientation
}

\author{
Mimi Hughes ANd Kelly M. MaHONEY \\ Cooperative Institute for Research in the Environmental Sciences, and NOAA/ESRL, Boulder, Colorado \\ PAUL J. NEIMAN \\ Physical Sciences Division, NOAA/Earth System Research Laboratory, Boulder, Colorado \\ BENJAMIN J. MOORE \\ Department of Atmospheric and Environmental Sciences, University at Albany, State University of New York, \\ Albany, New York \\ Michael AleXANDER AND F. MARTin RALPH* \\ NOAA/Earth System Research Laboratory/Physical Sciences Division, Boulder, Colorado
}

(Manuscript received 8 October 2013, in final form 4 April 2014)

\begin{abstract}
This manuscript documents numerical modeling experiments based on a January 2010 atmospheric river (AR) event that caused extreme precipitation in Arizona. The control experiment (CNTL), using the Weather Research and Forecasting (WRF) Model with 3-km grid spacing, agrees well with observations. Sensitivity experiments in which 1) model grid spacing decreases sequentially from 81 to $3 \mathrm{~km}$ and 2) upstream terrain is elevated are used to assess the sensitivity of interior precipitation amounts and horizontal water vapor fluxes to model grid resolution and height of Baja California terrain. The drying ratio, a measure of airmass drying after passage across terrain, increases with Baja's terrain height and decreases with coarsened grid spacing. Subsequently, precipitation across Arizona decreases as the Baja terrain height increases, although it changes little with coarsened grid spacing. Northern Baja's drying ratio is much larger than that of southern Baja. Thus, ARs with a southerly orientation, with water vapor transports that can pass south of the higher mountains of northern Baja and then cross the Gulf of California, can produce large precipitation amounts in Arizona. Further experiments are performed using a linear model (LM) of orographic precipitation for a central-Arizona-focused subdomain. The actual incidence angle of the AR $\left(211^{\circ}\right)$ is close to the optimum angle for large region-mean precipitation. Changes in region-mean precipitation amounts are small $(\sim 6 \%)$ owing to AR angle changes; however, much larger changes in basinmean precipitation of up to $33 \%$ occur within the range of physically plausible AR angles tested. Larger LM precipitation sensitivity is seen with the Baja-terrain-modification experiments than with AR-angle modification.
\end{abstract}

* Current affiliation: Scripps Institution of Oceanography, La Jolla, California.

Corresponding author address: Mimi Hughes, NOAA/Earth System Research Laboratory, Physical Sciences Division, Mail Code R/PSD2, 325 Broadway, Boulder, CO 80305.

E-mail: mimi.hughes@noaa.gov

\section{Introduction}

Wintertime precipitation along the west coast of the United States often occurs as the result of large water vapor fluxes from atmospheric rivers (ARs)-long, narrow, low-level plumes of enhanced water vapor transport (Zhu and Newell 1998)_-impinging on local topography. When AR-containing cyclones make landfall on the western 
U.S. coast, their enhanced vertically integrated water vapor transport (IVT) [see Eq. (1) in section 2c] combines with near-neutral moist static stability (Ralph et al. 2005; Neiman et al. 2008a) and strong orographic forcing (e.g., Smith et al. 2010) to produce large amounts of precipitation (Neiman et al. 2008b; Dettinger et al. 2004). Consequently, AR storms have been linked with flooding and are a critical component of the water budget of the western United States (Ralph et al. 2006; Dettinger 2011; Dettinger et al. 2012).

Although much headway has been made documenting the importance of ARs to extreme precipitation on the west coast of the United States, only a few studies have documented the impact of ARs across the Intermountain West (Leung and Qian 2009; Rutz and Steenburgh 2012; Rutz et al. 2014; Rivera et al. 2014). The first part of this two-part series (Neiman et al. 2013, hereafter Part I) examined a sequence of three strong flood-producing AR events that occurred in late January 2010 and produced large amounts of precipitation across the southwestern United States. In many locations across the southwestern United States, this series of storms ranked in the top $5 \%$ of precipitation events since 1950, and it caused record precipitation and widespread flooding, especially across the central Arizona Mogollon Rim, which stretches from northwest to southeast across central Arizona (see Fig. 1d). The strongest AR, and the last in the sequence, formed north of Hawaii on 19 January 2010. It moistened via water vapor convergence and strong latent heat fluxes within the marine boundary layer, made landfall, and moved inland from 20 to 22 January 2010. The strong IVT associated with this AR, combined with its moist neutral stratification that allowed strong ascending airflow as the AR crossed Arizona's complex topography (e.g., Rotunno and Ferretti 2001), resulted in widespread precipitation, while the AR's high melting levels and soils saturated by the preceding AR events contributed to widespread flooding. The resultant orographic precipitation and hydrological impacts from the AR of 20-22 January were comparable to those typically observed with landfalling ARs in the West Coast mountains. Because of the severity of this series of storms, including loss of life during impact, the meteorology and National Weather Service (NWS) response were the subject of a multioffice NWS local service assessment (P. Iñiguez, Phoenix Weather Forecast Office, 2013, personal communication).

Inland-penetrating ARs encounter the mountainous terrain of the western United States, which plays an important role in determining water vapor loss along the storm's path. Part I postulated that for this specific event, the upstream topography was particularly critical in determining downstream precipitation amounts: "the intense character of the incoming vapor fluxes was partly a consequence of the precise positioning of the AR across the relatively low mountains of southern Baja south of $30^{\circ} \mathrm{N}$ (rather than across the much higher, northern portion of this range) and west of Mexico's Sierra Madre Occidental, because only a fraction of the water vapor within the AR over the eastern Pacific was likely lost to orographic processes upwind of Arizona" (p. 482). We test this observationally based hypothesis using two sensitivity experiments with the Weather Research and Forecasting (WRF) Model. We first coarsen the WRF terrain, which impacts the height of the mountains, as well as the gradients associated with them; we focus on the reduction of Baja California terrain height due to reduced terrain grid spacing in this experiment. In the second experiment, we artificially increase the Baja terrain height to simulate AR passage across higher topographical barriers (e.g., southern versus northern Baja). The goal of these experiments is to quantify how critical the passage of this AR across loweraltitude southern Baja was to precipitation amounts in Arizona by modifying WRF's terrain.

While the magnitude of water vapor fluxes incident on topography is a first-order determinant of resultant precipitation (e.g., Roe 2005; Smith 2006), the projection of those fluxes onto local terrain also determines precipitation magnitude. As the direction of the incoming water vapor fluxes is rotated, the magnitude of the dot product between the terrain gradient and those fluxes changes, modulating precipitation response (e.g., Smith 1979; Smith and Barstad 2004). A few studies have suggested that AR angle is critical in determining local precipitation response because of its orientation relative to both upstream and local topography (Ralph et al. 2003; Neiman et al. 2011). The third experiment in this manuscript quantifies the impact of AR angle on regionwide and basin-scale precipitation amounts, utilizing the onelayer linear model (LM) of orographic precipitation (Smith 2003; Smith and Barstad 2004) to artificially "rotate" the AR that impacts the Arizona Mogollon Rim while keeping AR IVT magnitude fixed. We then use the LM on output from the terrain-modification WRF experiments so that AR-angle sensitivity can be directly compared with AR IVT magnitude sensitivity.

\section{Model, data, and methods}

\section{a. WRF simulations}

The sensitivity of precipitation to terrain height is tested using a set of nine simulations generated with WRF, version 3.3.1 (Skamarock et al. 2008). To focus on the primary AR event from Part I, each simulation begins at 1800 UTC 20 January and runs for $48 \mathrm{~h}$, ending at 1800 UTC 22 January 2010. Six of the nine simulations use the same $699 \times 699$ gridpoint atmospheric domain with 3-km 

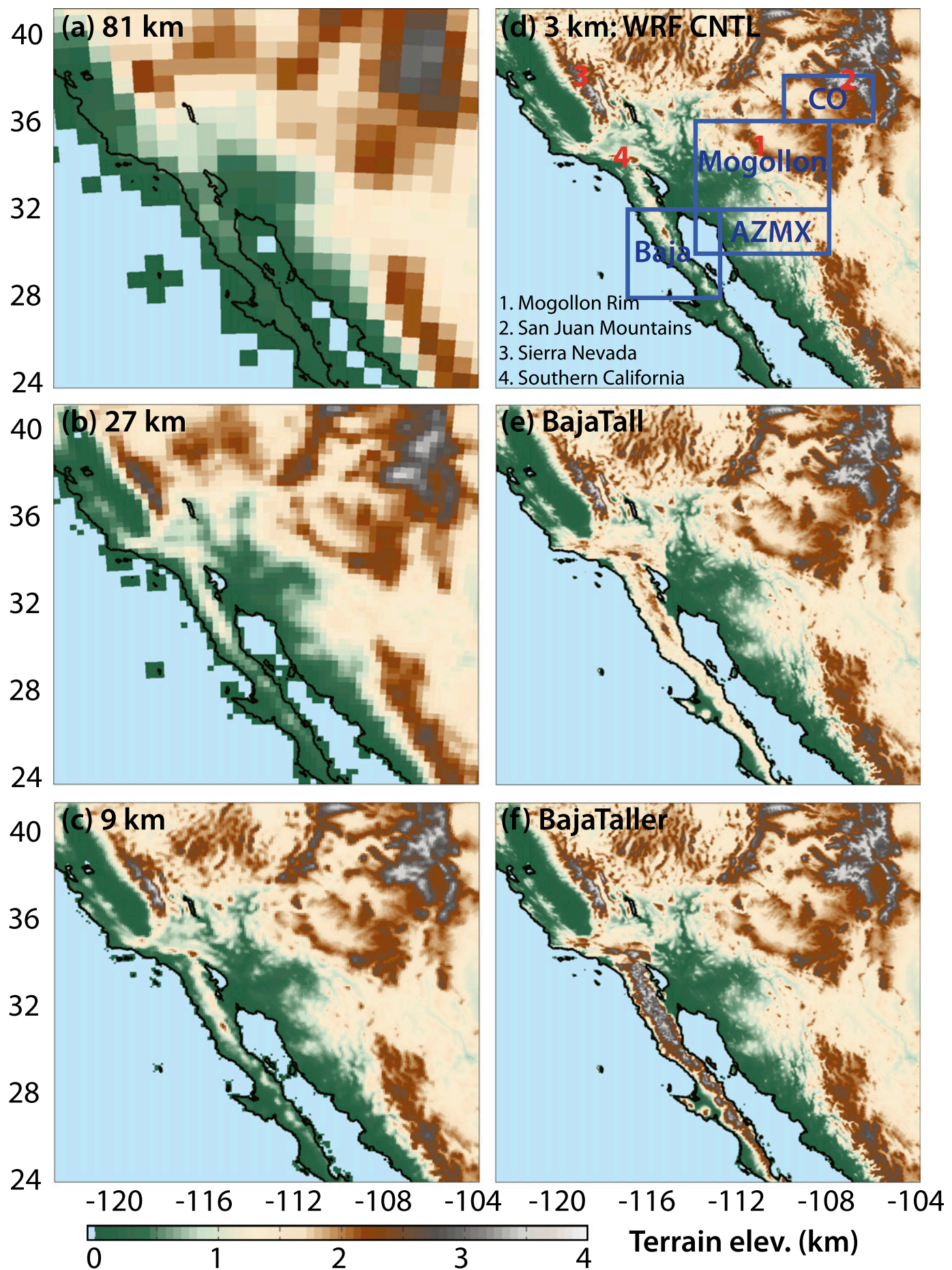

FIG. 1. Terrain height in the WRF simulations (km; color fill): (a) 81-km resolution, (b) 27-km resolution, (c) 9-km resolution, (d) 3-km resolution, (e) 3-km BajaTall, and (f) 3-km BajaTaller. Blue boxes in (d) show the four subregions used in Fig. 5, three of which are used in Fig. 2c and one in Figs. 10-13. Red numbers in (d) mark four locations referred to in the text, with key at bottom left of (d). Black line shows actual coastline. 
TABLE 1. List of WRF simulations and their abbreviations in the text.

\begin{tabular}{lccc}
\hline Simulation & $\begin{array}{c}\text { Terrain } \\
\text { resolution }(\mathrm{km})\end{array}$ & $\begin{array}{c}\text { Atmospheric } \\
\text { resolution }(\mathrm{km})\end{array}$ & Other notes \\
\hline CNTL & 3 & 3 & Uses Kain-Fritsch convective parameterization \\
9L9A & 9 & 9 & Uses Kain-Fritsch convective parameterization \\
9L3A & 9 & 3 & \\
27L27A & 27 & 27 & Uses Kain-Fritsch convective parameterization \\
27L3A & 27 & 3 & Terrain across Baja raised so that gaps through terrain are "filled in," \\
81L81A & 81 & 3 & and max elev is similar to Baja max in CNTL. \\
81L3A & 81 & 3 & Terrain across Baja raised so that gaps through terrain are "filled in," \\
Tall & 3 & 3 & and max elev is similar to Mogollon region max in CNTL. \\
Taller & 3 & & \\
\hline
\end{tabular}

grid spacing for the model atmosphere and use identical physics parameterizations [control (CNTL), 9L3A, 27L3A, 81L3A, Tall, and Taller; see Table 1 for short descriptions of each simulation]. The physics parameterizations used for these six simulations are Thompson microphysics (Thompson et al. 2008), explicit convection (i.e., no cumulus scheme is used ${ }^{1}$ ), rapid radiation transfer model longwave radiation (Iacono et al. 2008), Dudhia shortwave radiation (Dudhia 1989), Noah land surface model (Chen and Dudhia 2001), and the Yonsei University planetary boundary layer scheme (Hong et al. 2006) with a MoninObukhov surface layer. The other three simulations cover the same geographical area as the previous six, but they have atmospheric resolution commensurate with their coarsened terrain (9L9A, 27L27A, and 81L81A) and thus have fewer grid points. These three simulations also use the Kain-Fritsch cumulus parameterization (Kain 2004) rather than explicit convection because of their coarsened atmosphere. All simulations have 54 vertical levels and use the National Centers for Environmental Prediction (NCEP) Climate Forecast System Reanalysis (CFSR) as lateral boundary conditions (see section $2 b$ ).

Terrain from the WRF simulations is shown in Fig. 1. The CNTL is a standard WRF simulation using $3-\mathrm{km}$ atmospheric grid spacing atop model terrain with $3-\mathrm{km}$ grid spacing generated using the WRF preprocessing system (WPS); terrain of the three coarse-atmosphere simulations (9L9A, 27L27A, and 81L81A) is generated similarly. We then used two different methods to modify terrain while keeping WRF grid spacing (i.e., atmospheric resolution) constant at $3 \mathrm{~km}$. First, the terrain for the three coarse-resolution-terrain, fine-resolution-atmosphere simulations (81L3A, 27L3A, and 9L3A) was generated

\footnotetext{
${ }^{1}$ Sensitivity to having no cumulus scheme at 3 -km grid spacing was tested by running an identical 3-km simulation with the Kain-Fritsch cumulus parameterization. Resulting precipitation in this additional simulation was comparable to CNTL over land (not shown).
}

using WPS, then the coarse-resolution terrain was interpolated using the nearest-neighbor technique to the $3-\mathrm{km}$ grid used in CNTL. For the second method, two simulations were conducted in which the terrain in the Baja peninsula was altered. In the "BajaTall" simulation, the existing terrain height was increased by a factor of 5 for lower $(<300 \mathrm{~m})$ elevations, and the height increase factor was decreased steadily for higher elevations, topping out with an increase factor of 1.1 for the highest elevations (over $2500 \mathrm{~m}$ ). Thus, the maximum terrain height was increased by less than $250 \mathrm{~m}$, but the rest of the terrain was increased to be more commensurate with the higher-elevation locations. These specific multiplication factors were chosen so that the maximum elevations across Baja did not increase much but "gaps" in the terrain were eliminated and low-elevation southern Baja was more comparable to northern Baja. In the "BajaTaller" simulation, the terrain was also altered, although using larger terrain height increase factors so that the maximum elevations across Baja were similar to maxima in the Mogollon region: lower $(<300 \mathrm{~m})$ elevations were increased by up to 7 times their original value, and the height increase factor was again decreased steadily for higher elevations, topping out with an increase factor of 1.4 for elevations over $2500 \mathrm{~m}$. Figures $1 \mathrm{e}$ and $1 \mathrm{f}$ illustrate the effect of these changes. We also smoothed terrain features at the northern edge of the altered terrain (where it meets the unaltered terrain of California) to eliminate unrealistically steep edges along the boundaries.

\section{b. WRF verification datasets}

In section 3, IVT from CNTL is compared with that from the CFSR (Saha et al. 2010). For our calculations, we retrieved the analyses on a $0.5^{\circ} \times 0.5^{\circ}$ grid and on pressure levels from 1000 to $300 \mathrm{hPa}$, spaced every $25 \mathrm{hPa}$ below $700 \mathrm{hPa}$ and every $50 \mathrm{hPa}$ above $700 \mathrm{hPa}$, at 0000 UTC 22 January 2010.

Section 3 also compares precipitation and water vapor transport variables from CNTL against observations 
used in Part I. The spatial distribution of 48-h total precipitation in CNTL is compared to the 6-hourly accumulated NCEP stage IV quantitative precipitation estimation (QPE) product (Lin and Mitchell 2005; Baldwin and Mitchell 1998), summed over the 48-h period starting at 1800 UTC 20 January and ending 1800 UTC 22 January 2010. Stage IV QPE is a nationally mosaicked, 4-km-resolution gridded precipitation estimate created from the multisensor (i.e., radar and gauge based) precipitation estimates created at each river forecast center. To assess the timing of WRF-generated precipitation, accumulated precipitation time series from three gauges in the Mogollon subregion that were presented in Part I (Workman Creek, Marshall Gulch, and Tucson) are compared to time series precipitation traces from CNTL at the nearest grid point. Along-AR bulk integrated water vapor (IWV) flux (see calculation method in section 2c) at Tucson was calculated using IWV measurements calculated from a dual-channel global positioning system (GPS) receiver at Tucson combined with a National Oceanic and Atmospheric Administration (NOAA) 449-MHz radar wind profiler (White et al. 2007) deployed $48 \mathrm{~km}$ northwest of the Tucson GPS receiver.

\section{c. Diagnostic calculations}

We calculate water vapor transport (VT) from wind $\mathbf{U}$ and specific humidity $q_{v}$ in both WRF simulations and CFSR. Prior to IVT calculation, WRF $\mathbf{U}$ and $q_{v}$ are interpolated from their native sigma coordinates to pressure levels every $25 \mathrm{hPa}$ from 1000 to $300 \mathrm{hPa}$. CFSR data are retrieved on pressure levels. From the pressure level data, we calculate layer-mean vapor transport every $50 \mathrm{hPa}$ [similar to the IVT calculation in Neiman et al. (2008b)]:

$$
\mathrm{VT}=\frac{1}{g} \int_{p_{n}}^{p_{n+1}} q_{v} \mathbf{U} d p,
$$

where $g$ is gravitational acceleration and $p$ is pressure. This calculation results in layer-mean VT every $50 \mathrm{hPa}$ from WRF data, which we then sum from 1000 to $300 \mathrm{hPa}$ (which should include the majority of the tropospheric water vapor content) to compute IVT.

Because direct observations of IVT are not available, we estimate along-AR bulk IWV flux from observed IWV and wind profiles (as in Part I; see footnote on p. 476) and then perform a similar calculation using WRF output at nearest grid points for comparison. Bulk IWV flux (Neiman et al. 2009) is defined as the product of IWV and winds in the "orographic controlling layer"the range of altitudes for which the upslope wind speeds correlate strongly with precipitation amounts. In this case, we have used observed winds between 1.0 and $1.5 \mathrm{~km}$ above mean sea level (MSL), as in Part I. An AR orientation from $220^{\circ}$ is assumed. The observed bulk IWV flux is then compared against CNTL bulk IWV flux calculated using a similar method. Specifically, the modeled bulk IWV flux is calculated using IWV at the grid point closest to the Tucson GPS receiver and modelaveraged winds in the layer between 900 and $850 \mathrm{hPa}$ (i.e., $\sim 1.0-1.5 \mathrm{~km} \mathrm{MSL}$ ) at the grid point closest to the $449-\mathrm{MHz}$ wind profiler location.

To quantify the impact of the Baja California topography on downstream moisture, we calculate the drying ratio (DR) for the nine WRF simulations in section 4. The DR is calculated using the formula from Kirshbaum and Smith (2008):

$$
\mathrm{DR}=1-\frac{\mathrm{IWT}_{\text {downstream }}}{\mathrm{IWT}_{\text {upstream }}}
$$

where IWT is total water transport, calculated exactly as IVT except using total atmospheric water content (i.e., the sum of water vapor, liquid, and ice) rather than water vapor content. The details of our calculation are discussed in section 4 .

\section{d. Linear model of orographic precipitation}

The AR-angle sensitivity experiments of section 5 use the one-layer linear model of orographic precipitation developed in Smith (2003) and Smith and Barstad (2004), applied to the terrain of the CNTL simulation (i.e., 3-km grid spacing) and extended to account for upstream drying effects as described in Smith and Evans (2007). Here we describe this model briefly; more thorough descriptions and examples of its use can be found in Smith et al. (2005), Smith and Evans (2007), Hughes et al. (2009), and Lundquist et al. (2010). The LM describes the pattern of precipitation arising from forced ascent of saturated air over topography, where the vertical rate of ascent is determined from linear mountain wave theory. Forced ascent in the LM converts moist air to cloud water, which then converts to hydrometeors with time scale $\tau_{c}$ and fall out with time scale $\tau_{f}$. The hydrometeors and cloud water are advected by a mean wind $\mathbf{U}=U \mathbf{i}+V \mathbf{j}$. The $\mathrm{LM}$ also includes a gravity wave term allowing the mountainwave-induced change of vertical velocity with height to cause precipitation to fall upstream of topography gradients. Thus, in the LM, precipitation broadly scales with the gradient of the terrain, modified by advection and gravity wave processes. For convenience, the LM operates in Fourier space, where representations of physical processes can be combined into a single transfer function. A background precipitation rate, representing 
the precipitation falling at zero elevation far from topographical influence, is then added to the inverse Fourier transform. The solution is then truncated to eliminate negative values.

Smith and Evans (2007) illustrate how the relationship between the water vapor flux far upstream, the drying ratio, and the local precipitation can be combined to incorporate the effects of airstream drying into the linear model. Prior to accounting for drying, the reference LM precipitation amount $P_{\text {ref }}$ depends on the water vapor transport far upstream, $\mathrm{IVT}_{0}$. The local precipitation is then assumed to be this reference precipitation modified by the drying ratio [Eq. (2)]:

$$
P(x, y)=P_{\text {ref }}(x, y) \times[1-\operatorname{DR}(x, y)] .
$$

Then, the relationship between the drying ratio and reference precipitation is invoked, and the first-order differential equation that results is solved to relate the local precipitation directly to the reference precipitation and water vapor transport far upstream:

$P(x, y)=P_{\text {ref }}(x, y) \times \exp \left[-\int_{\text {upstream }}^{x, y} \frac{P_{\text {ref }}(x, y) d s}{\left|\mathrm{IVT}_{0}\right|}\right]$,

where the integral is calculated along the wind direction, and thus $d s=(U d x+V d y) /|\mathbf{U}|$.

Although another extension of the LM incorporating multiple layers has recently been developed (Barstad and Schüller 2011), the simpler one-layer version is more appropriate to investigate the impact of modifying (via angle and terrain height) impinging IVT on the precipitation distribution since IVT is a vertically integrated quantity.

\section{Comparison of CNTL with observations}

To assess WRF's ability to represent the meteorological processes critical to this event, and thus justify its use for the subsequent experiments, we first compare the CNTL precipitation with observations. Figures $2 a$ and $2 b$ show the 48-h (from 1800 UTC 20 January to 1800 UTC 22 January 2010) total precipitation from NCEP's stage IV QPE product and CNTL, respectively, where locations with missing data in stage IV have been masked out in CNTL. Visual comparison of these two figures illustrates that CNTL precipitation is quite realistic: both indicate large amounts of precipitation across southern California's mountains and the Mogollon Rim in Arizona, with moderate amounts in southwest Colorado's San Juan Mountains, and smaller amounts of precipitation across most of the southwestern United States. The agreement between the two datasets is confirmed by a high spatial correlation (correlation coefficient is 0.83 ). Figure $2 c$ compares areal mean and maximum precipitation amounts for three of the four subregions of Fig. 1b: the areal mean precipitation in the Mogollon subregion (i.e., blue box labeled "Mogollon" in Fig. 1d) in WRF is $57.99 \mathrm{~mm}, \sim 5 \%$ greater than the stage IV mean precipitation of $55.4 \mathrm{~mm}$, although the maximum precipitation in the Mogollon region is $\sim 20 \%$ larger in WRF (315 versus $263 \mathrm{~mm}$ ). The spatial distribution of precipitation in the San Juan Mountains in southwestern Colorado is similar in the model and observations, but CNTL precipitation is $30 \%-40 \%$ larger. Comparable agreement is seen in the Arizona/Mexico (AZ/MX) subregion. Given stage IV's known underrepresentation over complex terrain (e.g., Zhang et al. 2012), these comparisons suggest that CNTL is capturing precipitation quite well throughout the regions of interest. In addition, simulations performed at 1-km grid spacing (not shown) have mean precipitation amounts within $3 \%$ of CNTL in all four regions, suggesting higher resolution would not improve the agreement with observations.

To assess precipitation timing, we also compare CNTL precipitation with three gauges over a range of elevations in the Mogollon subdomain that were first presented in Part I: Tucson (778 m MSL), Marshall Gulch (2171 m MSL), and Workman Creek (2103 m MSL) (Fig. 2d). At both Tucson and Workman Creek, the onset of precipitation is delayed in CNTL by a few hours, and overall precipitation is slightly underestimated in CNTL. At Marshall Gulch, CNTL precipitation leads observations slightly and overestimates precipitation. Nevertheless, given that these are point estimates compared directly against the CNTL $3-\mathrm{km}$ grid, the agreement is acceptable.

Since the precipitation over the Mogollon subdomain during this event was largely determined by the magnitude of the incoming IVT (Part I), we also compare CNTL IVT at 0000 UTC 22 January 2010 with CFSR and a time series of along-AR bulk IWV flux (Fig. 3). Although CFSR is not an independent verification dataset (since it was used as lateral boundary conditions), it (and other reanalysis datasets) provides gridded estimates of observed IVT and was qualitatively compared against satellite IWV estimates in Part I. Both CFSR and CNTL have southwesterly IVT greater than $1000 \mathrm{~kg} \mathrm{~m}^{-1} \mathrm{~s}^{-1}$ stretching across Baja California into Arizona. The largest difference between the two IVT maps is the finescale structure in IVT (e.g., sharp IVT gradients, especially in the core IVT region) in CNTL that is absent from CFSR owing to the latter's coarser horizontal resolution. The time series of IWV and bulk IWV flux (Fig. 3c) also show CNTL is successfully simulating this event, that is, the magnitude and timing of 

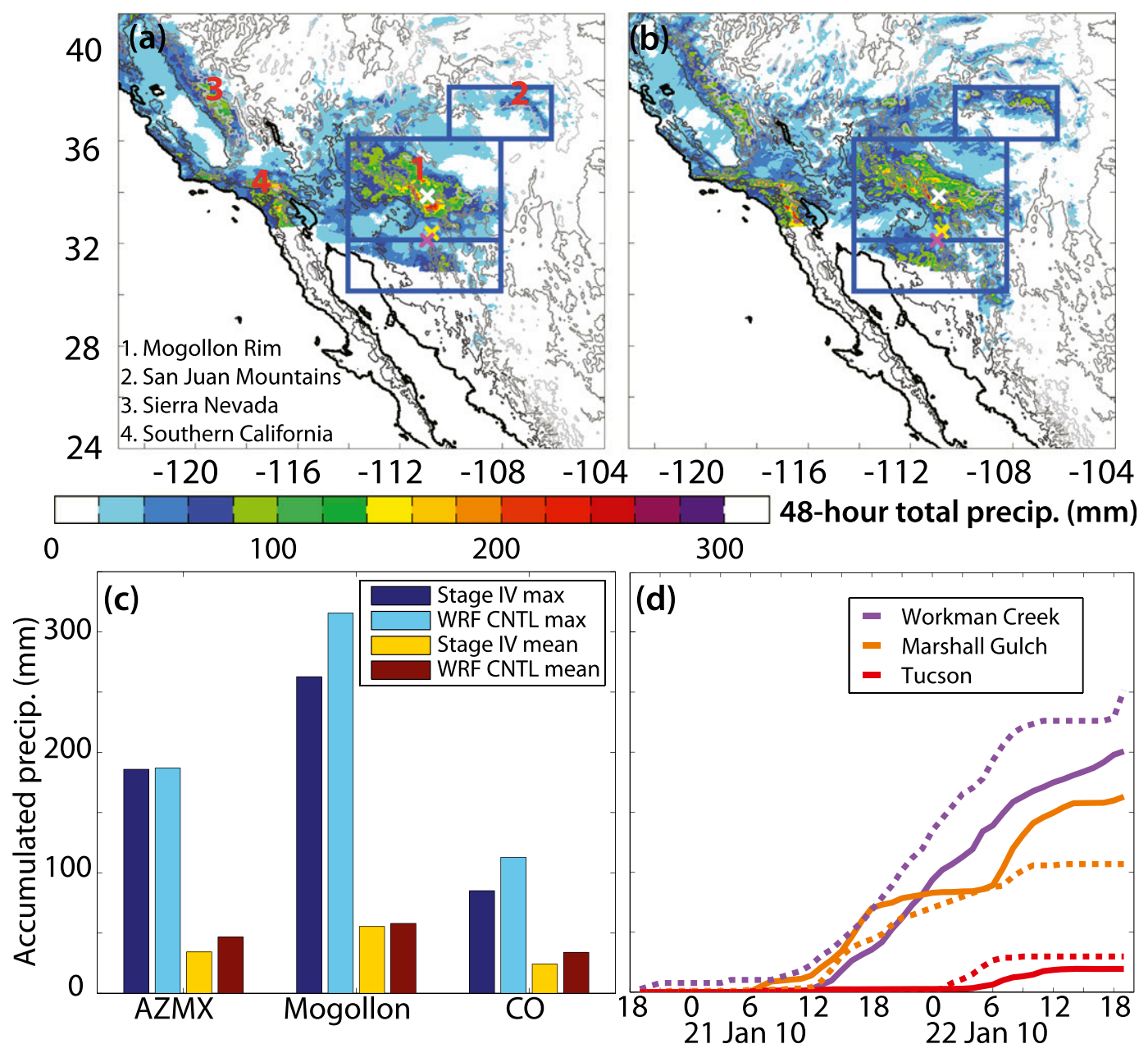

FIG. 2. The 48-h total precipitation (mm) ending at 1800 UTC 22 Jan 2010 from (a) stage IV QPE and (b) 3-km resolution CNTL WRF simulation, with missing data locations from (a) removed. White, yellow, and magenta crosses show locations of Workman Creek, Marshall Gulch, and Tucson gauges, respectively. Black line shows actual coastline, dark/medium/light gray contours show terrain at 500/1500/2500 m, and the three blue inset boxes are the same as the eastern three shown in Fig. 1d. Red numbers in (a) mark four locations referred to in the text, with key at bottom left of (a). (c) Subregion mean and max 48-h total precipitation (mm) ending at 1800 UTC 22 Jan 2010 from stage IV QPE and CNTL (see legend for colors). Missing data locations in stage IV QPE have been removed from CNTL prior to averaging. (d) Time series of precipitation accumulation (mm) from Tucson (red), Marshall Gulch (orange), and Workman Creek (purple) for observations (dashed) and closest CNTL grid point (solid).

strong IWV closely match the observed GPS measurements. In addition, CNTL closely matches the overall magnitude of observed along-AR bulk IWV flux and mirrors its observed increase on 21 January with a sudden reduction at 060022 January 2010 during the passage of a cold front.

\section{Terrain modification experiments}

The performance of CNTL compared with observations and reanalysis data confirm that WRF represents the dominant physical processes determining the distribution of precipitation during this event. In this section, we use WRF to test the sensitivity of precipitation to terrain elevation, both from the perspective of reduced terrain height due to coarse model resolution and by increasing the height of the upstream terrain in Baja California.

\section{a. Precipitation}

Figure 4 shows 48 -h total precipitation across the entire WRF domain for CNTL (Fig. 4g), the six terrainresolution sensitivity runs (81L81A, 27L27A, 9L9A, 81L3A, 27L3A, and 9L3A in Figs. 4a-f), and the two Baja California terrain-modification runs (Tall and Taller in Figs. $4 \mathrm{~h}$ and $4 \mathrm{i}$, respectively). All nine simulations exhibit 

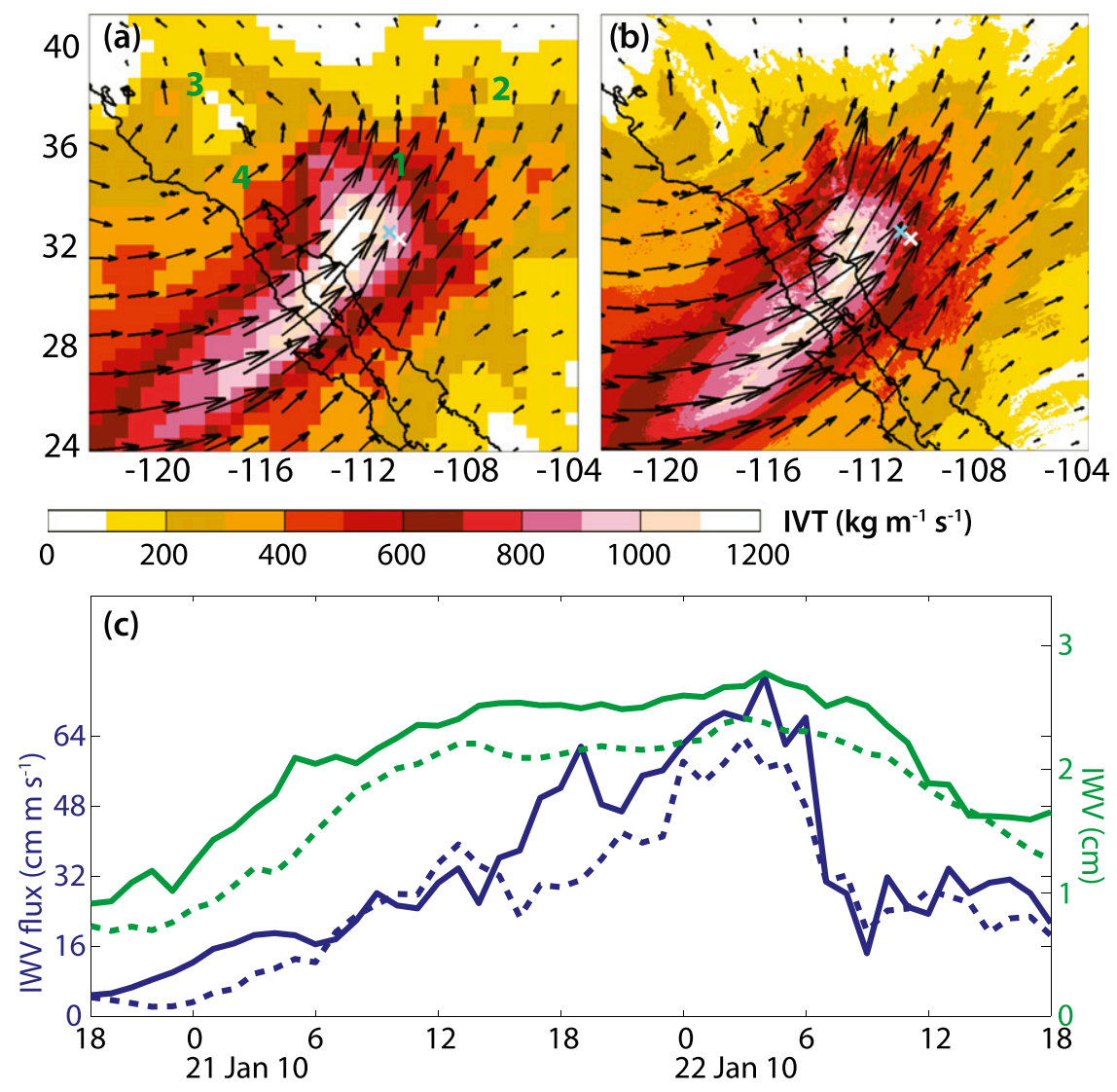

FIG. 3. IVT ( $\mathrm{kg} \mathrm{s}^{-1} \mathrm{~m}^{-1}$ ) in (a) CFSR and (b) CNTL at 0000 UTC 22 Jan 2010. Color contours and arrows show IVT magnitude, and arrows also show direction. Green numbers in (a) mark four locations referred to in the text, with key at bottom left of Fig. 2a. (c) Time series of hourly IWV (cm; green) and hourly, layer-mean, along-AR IWV flux $\left(\mathrm{cm} \mathrm{m} \mathrm{s}^{-1}\right.$; blue) observed with a wind profiler and GPS receiver near Tucson [dashed; from Neiman et al. (2013)] and closest CNTL grid point (solid). Note that for IWV flux calculation, we have used winds between 900 and $850 \mathrm{hPa}$ (i.e., $\sim 1.0-1.5 \mathrm{~km} \mathrm{MSL}$ ), whereas the corresponding observations are between 1.0 and $1.5 \mathrm{~km}$ MSL. Cyan and white crosses in (a) and (b) show locations of the Tucson 449-MHz wind profiler and GPS receiver, respectively.

two broad similarities. First, they all have extensive moderate precipitation $(20-40 \mathrm{~mm})$ throughout much of the domain, even in the absence of orographic forcing. Second, in all simulations, topography drives larger precipitation amounts, ranging from 60 to $100 \mathrm{~mm}$ in some places but exceeding $200 \mathrm{~mm}$ in many locations, including the Sierra Nevada, Baja California, northwestern Mexico/ southern Arizona, the Mogollon Rim in Arizona, and the San Juan Mountains in southwestern Colorado. Some large differences between the simulations are also immediately apparent: as terrain resolution decreases (i.e., moving from $3-\mathrm{km}$ terrain down to $81-\mathrm{km}$ terrain) less precipitation falls over Baja California. The sharp lines of large precipitation amounts at the edges of the terrain grid boxes in the coarse-land/fine-atmosphere simulations (Figs. 4d-f), most evident in Fig. 4d, are a direct result of coarse-resolution terrain sitting underneath finer-resolution atmosphere. Conversely, as the height of Baja California is increased in the Tall and Taller experiments, the amount of precipitation falling over Baja increases, and precipitation amounts immediately downstream (i.e., over the AZ/MX and Mogollon subregions of Fig. 1d) decrease with increased height along the spine of the Baja mountains.

To further quantify the differences in precipitation among the nine experiments, Fig. 5 shows the mean precipitation amounts (normalized by dividing by region mean of CNTL) across the four subregions shown in Fig. 1d. As illustrated in Fig. 4, mean precipitation amounts are reduced over Baja as terrain resolution is decreased, with the exception of simulation 9L9A. This decrease in precipitation over Baja implies a consequent increase in downstream IVT. Although this implied increase in downstream IVT further implies that mean precipitation 
(a) $81 \mathrm{~L} 81 \mathrm{~A}$

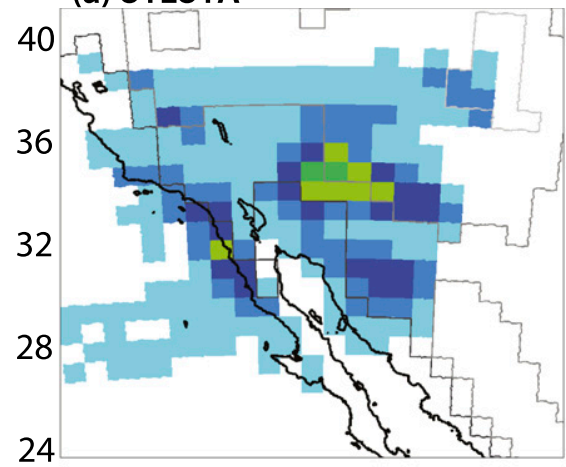

(b) 27L27A

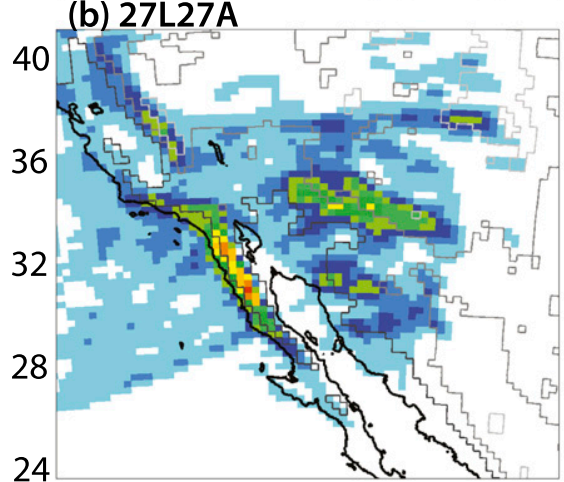

(c) 9 L9A

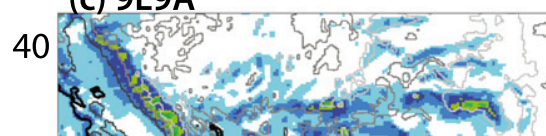

36

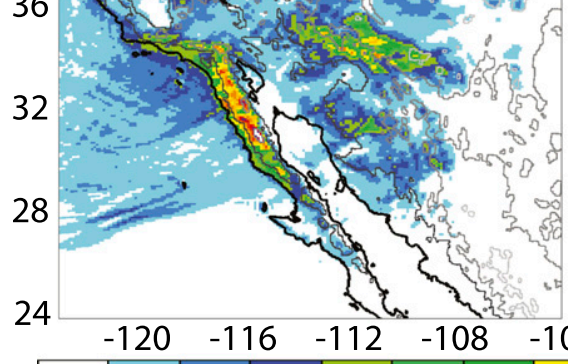

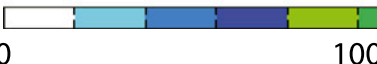

(d) $81 \mathrm{~L} 3 \mathrm{~A}$

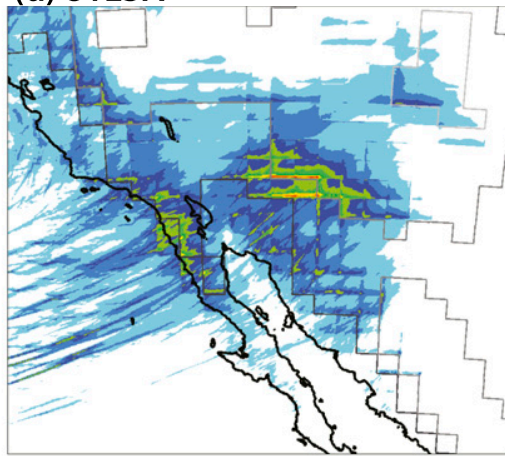

(e) 27L3A

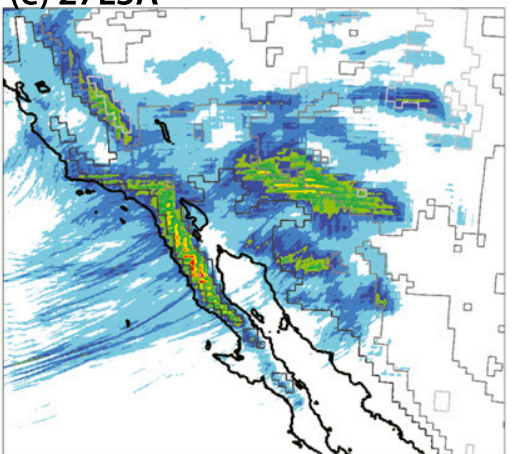

(f) $9 L 3 A$

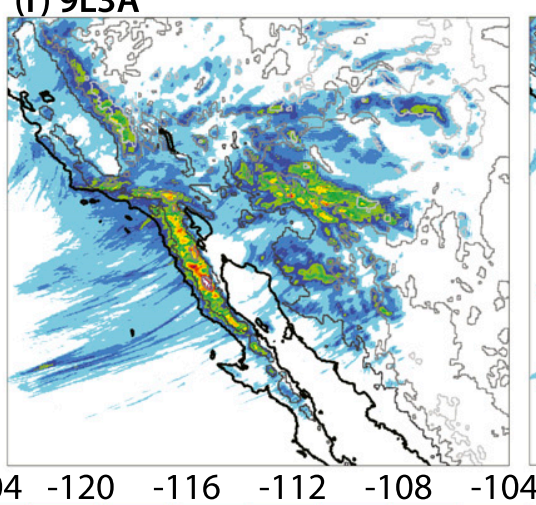

\section{(g) CNTL}

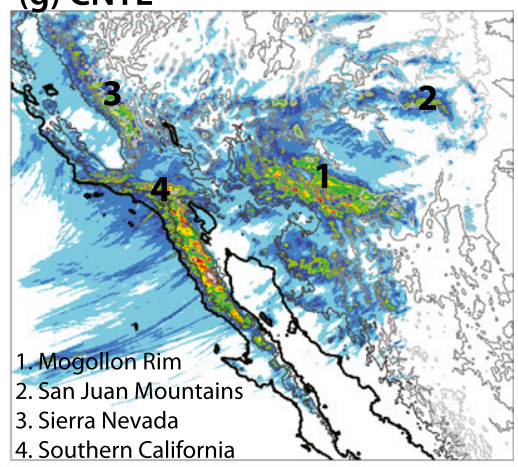

(h) Tall

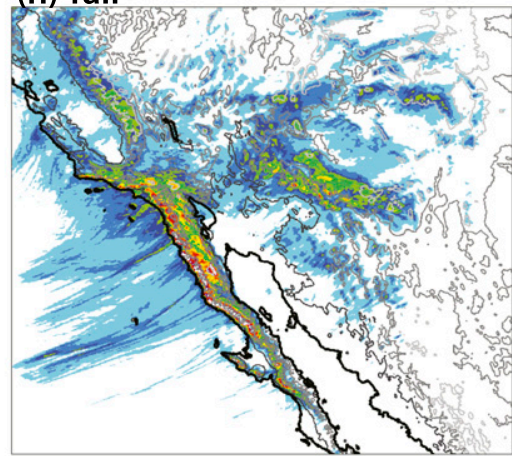

(i) Taller

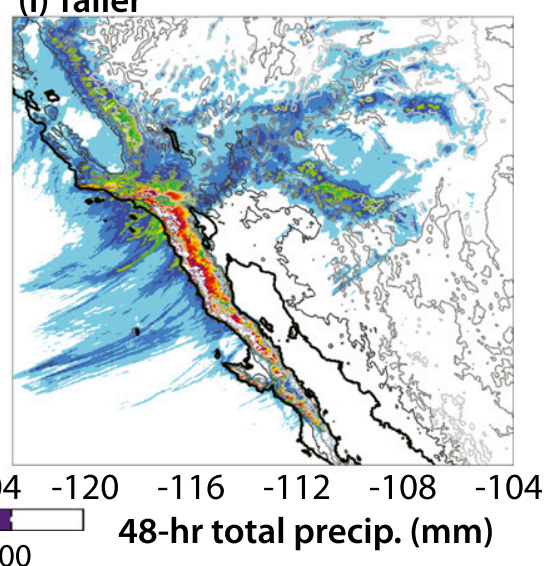

FIG. 4. The 48-h total precipitation (mm) ending at 1800 UTC 22 Jan 2010 in nine WRF simulations: (a) 81L81A, (b) 27L27A, (c) 9L9A, (d) 81L3A, (e) 27L3A, (f) 9L3A, (g) CNTL, (h) 3-km BajaTall, and (i) 3-km BajaTaller. Red numbers in (d) mark four locations referred to in the text, with key at bottom left of $(\mathrm{g})$. Black line shows actual coastline, and dark/medium/light gray contours show model terrain at $500 / 1500 / 2500 \mathrm{~m}$.

in $\mathrm{AZ} / \mathrm{MX}$ and the Mogollon should get larger as the terrain resolution gets coarser, the changes in region-mean precipitation amounts are small and variable. Mean precipitation in AZ/MX is largest in the 27L27A run and is generally larger in the coarse-atmosphere simulations than in those with coarse terrain/fine atmosphere. The opposite is true in the Mogollon region: mean precipitation increases steadily in the coarse-terrain/fine-atmosphere simulations, but remains nearly constant in the coarseatmosphere simulations. Mean precipitation in the San
Juan Mountains subregion generally increases as terrain resolution gets finer, although like the Baja region 9L9A has the largest region-mean precipitation. We hypothesize that these inconsistent changes in region-mean precipitation are caused primarily by the fundamental difference between using a convective parameterization with a coarse atmosphere and explicit convection over the fine atmosphere, confounded by the differences in terrain in the three interior regions. Because of the lack of a clear signal, we further explore the drying across Baja 
(a) Baja

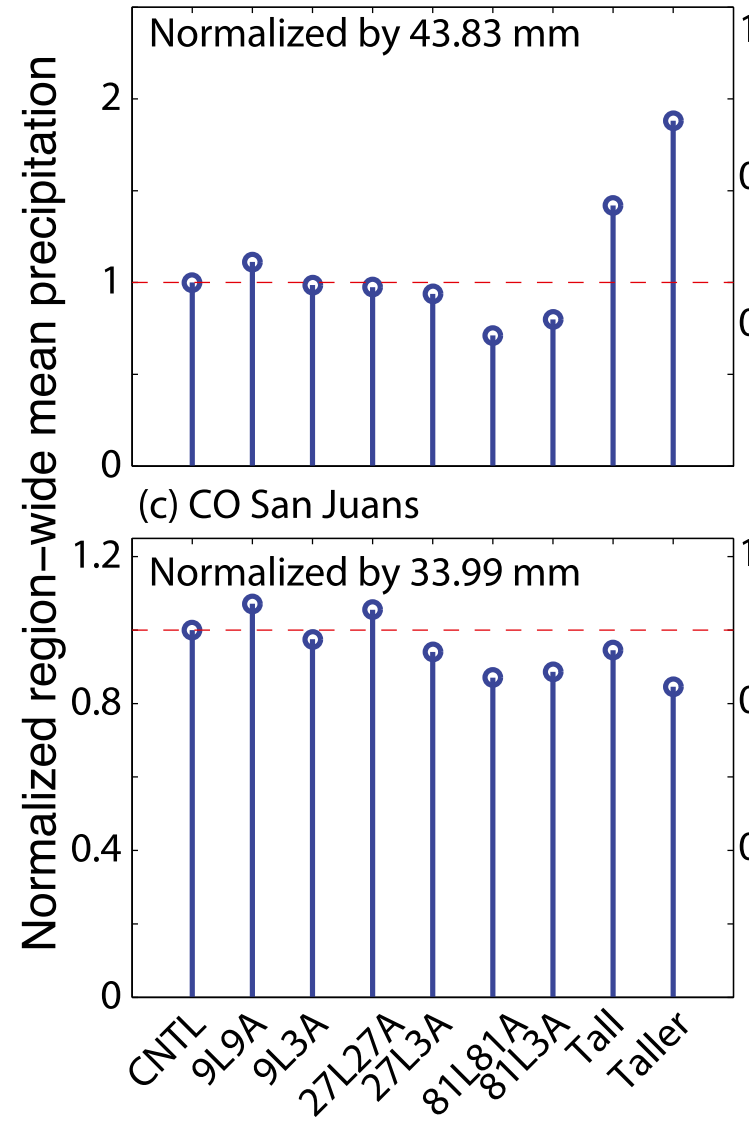

(b) Mogollon

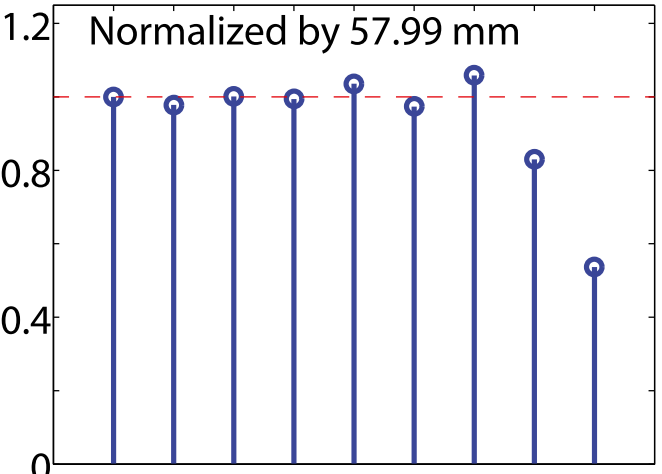

(d) AZ/MX border

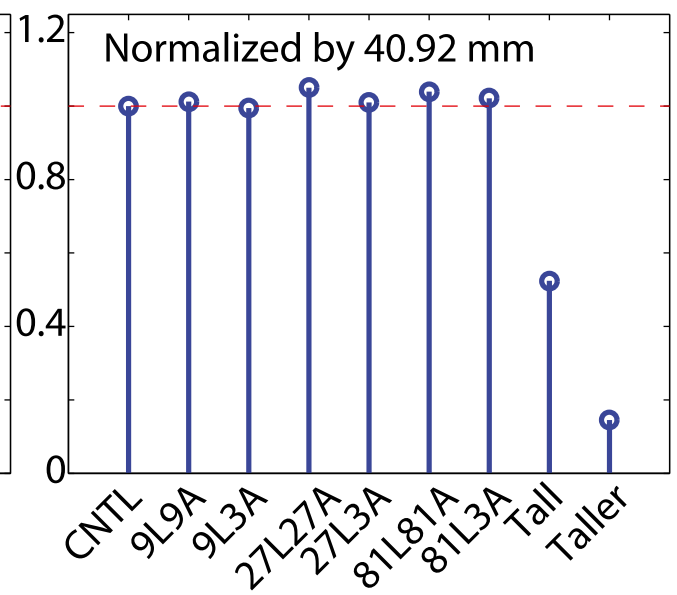

FIG. 5. Subregionwide mean 48-h total precipitation amount ending at 1800 UTC 22 Jan 2010 for the nine WRF simulations, normalized by the CNTL areal mean, for (a) Baja, (b) Mogollon, (c) San Juan Mountains, and (d) AZ/MX border. Subregions are shown in Fig. 1d. The amount each panel has been normalized $(\mathrm{mm})$ is shown at the top of each panel. Thin red dashed line shows $y=1$.

in section $4 \mathrm{~b}$ and the sensitivity of downstream precipitation amounts in section 5.

Mean precipitation amounts in the Tall/Taller experiments show a physically plausible pattern across the four subregions: as Baja terrain height increases, mean precipitation amounts over Baja also increase. This increased precipitation over Baja results in a subsequent decrease over the remaining three regions, which gets smaller as the region's terrain gets higher (i.e., largest reduction in mean precipitation amounts over AZ/MX, followed by the Mogollon, and the smallest reduction over the San Juan Mountains). This pattern is more pronounced in Taller than in the Tall experiment (i.e., it scales with the changes in the Baja terrain height).

\section{b. IVT and drying ratio}

Because precipitation in this case is largely driven by orographic processes (e.g., see Part I), precipitation amounts should to first order be related to the product of integrated water vapor transport and terrain gradient (e.g., Smith 2006). In this subsection, we investigate IVT in the different WRF experiments. Figure 6 shows IVT at 0000 UTC 22 January 2010, when the AR was positioned directly across Baja and Arizona. All simulations show IVT in excess of $1000 \mathrm{~kg} \mathrm{~s}^{-1} \mathrm{~m}^{-1}$ southwest of Baja, oriented from southwest to northeast across Baja and impinging on the Mogollon Rim in Arizona, with broadly similar features. With the exception of 81L81A, these IVT values greater than $1000 \mathrm{~kg} \mathrm{~s}^{-1} \mathrm{~m}^{-1}$ extend southwestward from central Baja California in a sharp band to approximately $26^{\circ} \mathrm{N}, 120^{\circ} \mathrm{W}$, suggestive of strong convergence ahead of a surface cold front. Focusing first on the terrain-resolution runs, we see a very slight increase in the area downstream of Baja with IVT over $1100 \mathrm{~kg} \mathrm{~m}^{-1} \mathrm{~s}^{-1}$ as terrain resolution decreases, likely due to decreased rainout over Baja resulting from the lowering of terrain height there. This increase is more apparent in the coarse-atmosphere simulations (Figs. 6a-c) than in the coarse-terrain/fine-atmosphere simulations (Figs. 6d-f). Likewise, the large precipitation amounts 
(a) $81 \mathrm{~L} 81 \mathrm{~A}$

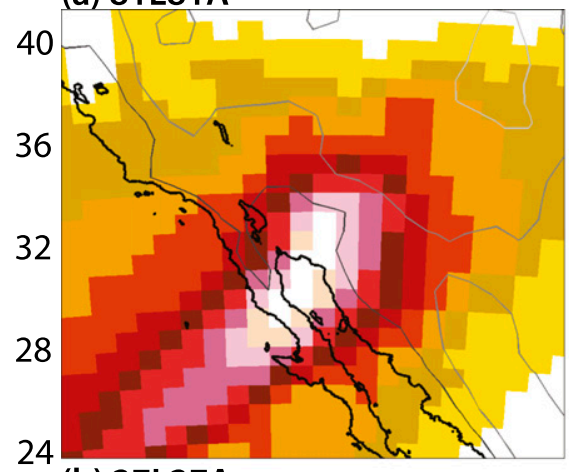

(b) 27L27A

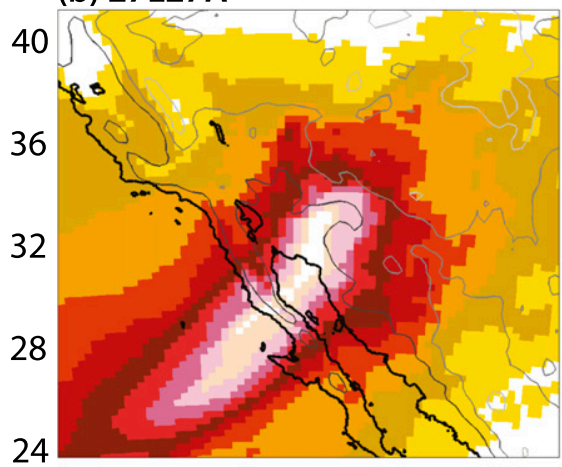

(c) 9 L9A

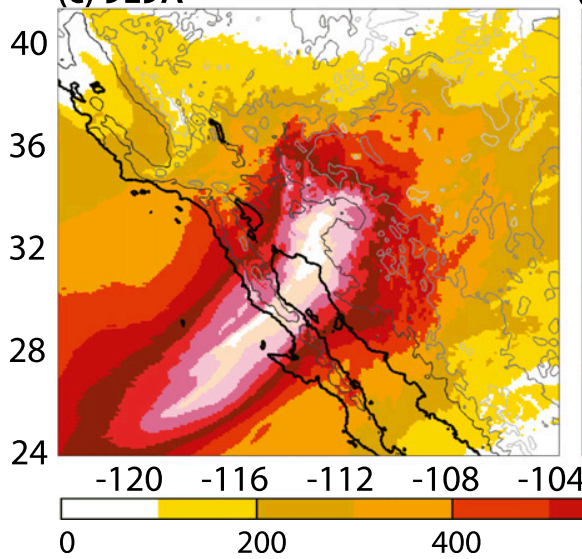

(d) $81 \mathrm{~L} 3 \mathrm{~A}$

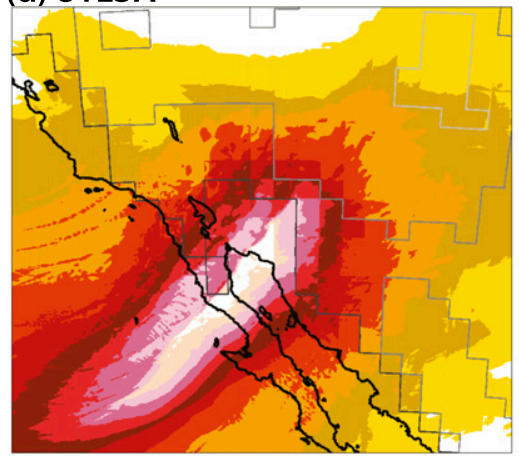

(e) 27L3A

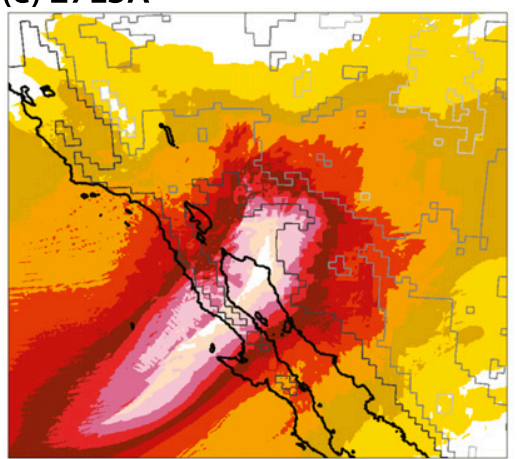

(f) $9 \mathrm{~L} 3 \mathrm{~A}$

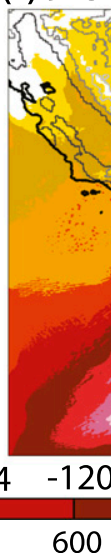

(g) CNTL

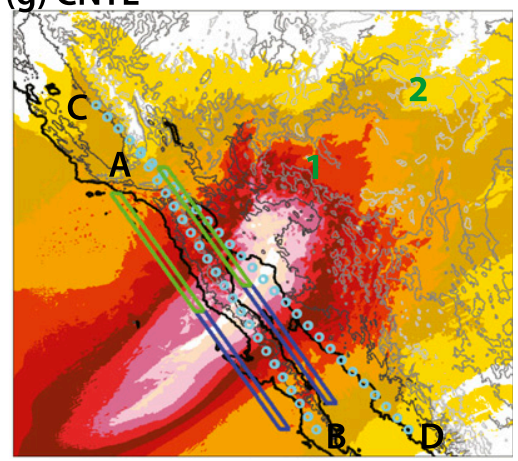

(h) Tall

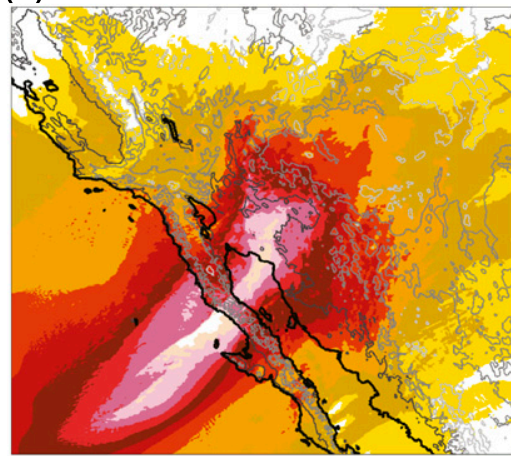

(i) Taller

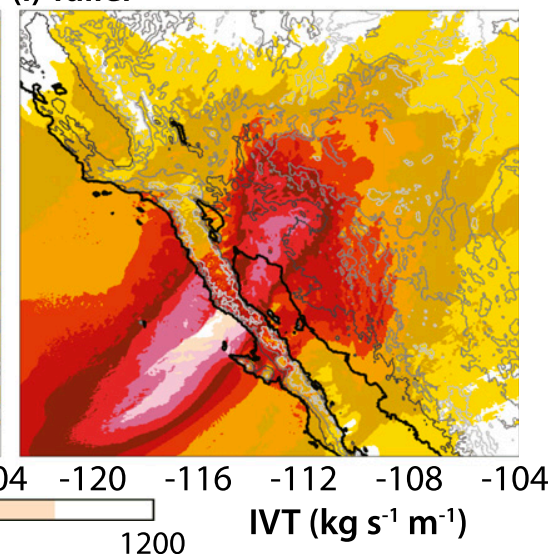

FIG. 6. IVT ( $\mathrm{kg} \mathrm{s}^{-1} \mathrm{~m}^{-1}$; color fill; integrated from 1000 to $300 \mathrm{hPa}$ ) at 0000 UTC 22 Jan 2010 in nine WRF simulations (as in Fig. 4). The lines A-B and C-D composed of cyan circles in (g) show locations of cross sections in Figs. 7 and 8, respectively. Green and blue boxes in (g) show northern and southern Baja regions used in drying ratio calculations in Fig. 9. Green numbers 1 and 2 in (g) show the two locations referred to in the text, with key at bottom left of Fig. 2a. Black line shows actual coastline, and dark/medium/light gray contours show terrain at 500/1500/2500 m.

across Baja in the Tall/Taller experiments illustrated in Figs. 4 and 5 are consistent with a dramatic reduction of IVT immediately downstream (i.e., northeast) of Baja.

To provide a vertical perspective on how the topography is modifying water vapor transport, we show two vertical cross sections of along-AR VT at the same time as the maps of IVT, 0000 UTC 22 January 2010 (Figs. 7 and 8; projection lines $\mathrm{A}-\mathrm{B}$ and $\mathrm{C}-\mathrm{D}$, respectively, shown in Fig. 6g). Along the spine of Baja (Fig. 7, cross section A-B) just south of $31^{\circ} \mathrm{N}$, all simulations show VT greater than $120 \mathrm{~kg} \mathrm{~m}^{-1} \mathrm{~s}^{-1}$ that extends from the surface (which varies in altitude) to $3 \mathrm{~km}$ MSL in the terrain-resolution simulations and CNTL and extends to $3.5 \mathrm{~km}$ in Tall and $4 \mathrm{~km}$ MSL in Taller. The 9L9A, 9L3A, CNTL, Tall, and, in particular, Taller simulations also have strong water vapor transport (i.e., greater than $60 \mathrm{~kg} \mathrm{~m}^{-1} \mathrm{~s}^{-1}$ ) through the narrow gaps in the mountains between $28^{\circ}$ and $30^{\circ} \mathrm{N}$ (these gaps do not exist in 
(a) $81 \mathrm{~L} 81 \mathrm{~A}$

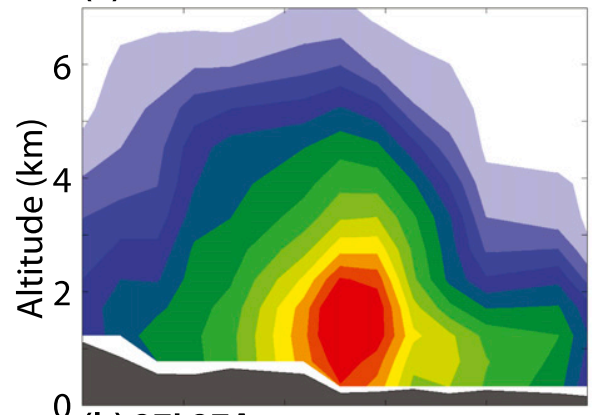

(b) 27L27A

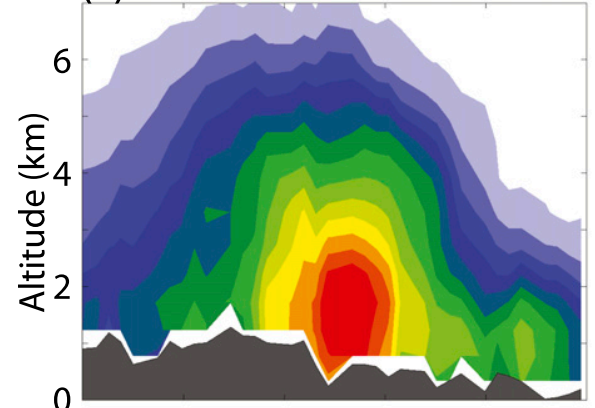

(c) 9 L9A

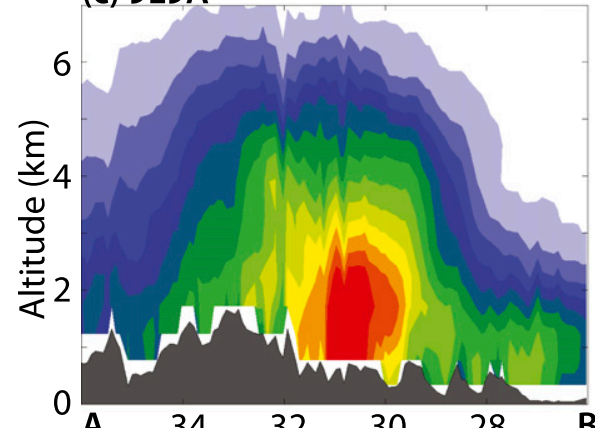

(d) $81 \mathrm{~L} 3 \mathrm{~A}$

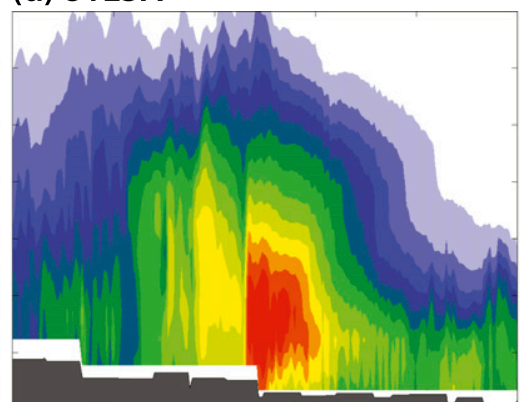

(e) 27L3A

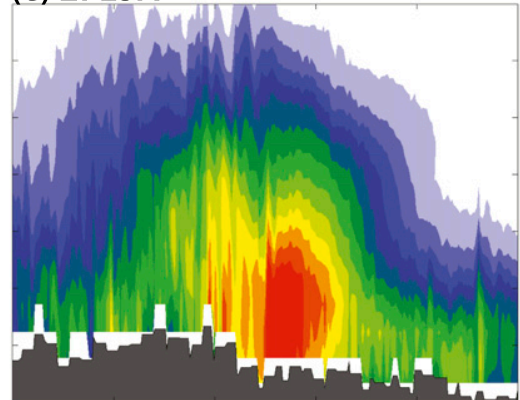

(f) $9 \mathrm{~L} 3 \mathrm{~A}$

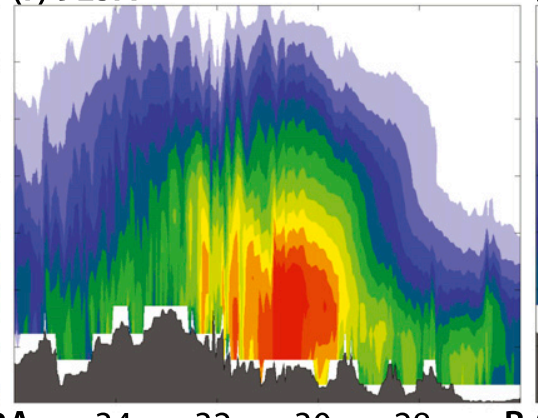

(g) CNTL

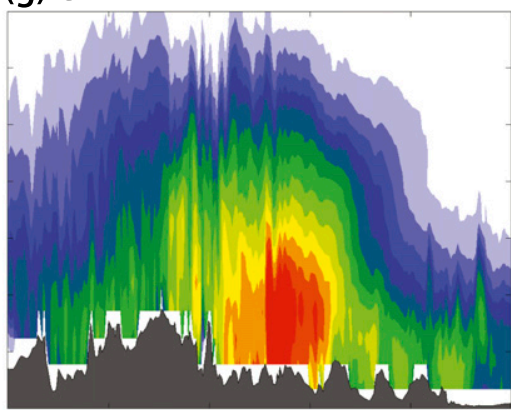

(h) Tall

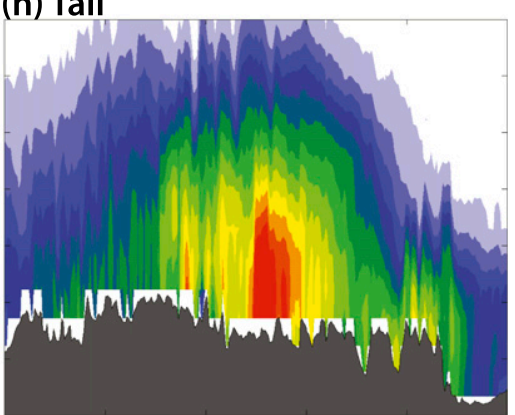

(i) Taller

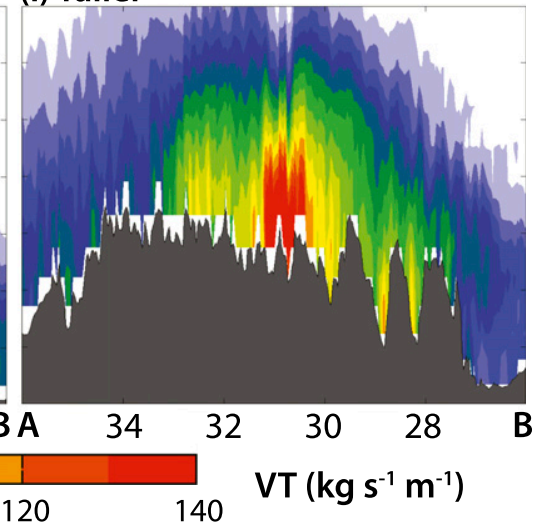

FIG. 7. Cross section along the spine of Baja (line A-B on Fig. $6 \mathrm{~g}$ ) of along-AR VT $\left(\mathrm{kg} \mathrm{s}^{-1} \mathrm{~m}^{-1}\right.$; color fill) at $0000 \mathrm{UTC} 22 \mathrm{Jan} 2010$ in nine WRF simulations (as in Fig. 4). The line of cyan circles A-B in Fig. $6 \mathrm{~g}$ shows the location of this cross section. Gray shading shows model terrain along this cross section. VT values have been calculated on pressure levels every $50 \mathrm{hPa}$ (e.g., $975 \mathrm{hPa}, 925 \mathrm{hPa}$, etc.). Terrain in the coarse-atmosphere simulations (e.g., 81L81A) appears different than terrain in the fine-atmosphere simulation with the same land resolution (e.g., 81L3A) because of a contouring artifact (i.e., these are not raster-fill images).

terrain coarser than 9-km grid spacing). Examination of the two variables that make up VT-wind and specific humidity (not shown) - reveals that water vapor is very small above about $3 \mathrm{~km}$ MSL in all simulations, and the increase in VT between 3 and $4 \mathrm{~km}$ MSL in the Tall and Taller experiments compared with CTNL is caused by much stronger winds at those altitudes. As was visible in the IVT plan views of Fig. 6, the sharpness of the VT gradient north of the region of strongest transport is strongly related to atmospheric resolution (cf. Fig. 7a versus Fig. 7d). Across Baja, 81L81A and 81L3A has substantially more total atmosphere between 0 and $3 \mathrm{~km}$ than CNTL, resulting in a slight increased depth over which the large VT values exist because of the reduced terrain height; this is due entirely to large specific humidity values at these lower elevations (not shown). Thus, as terrain height increases, more water vapor is removed by the terrain and VT decreases, except when winds are accelerated over the higher terrain.

Downstream of Baja California (Fig. 8), the impact on VT of the Baja terrain is even more apparent that it was along the spine of Baja: as terrain resolution decreases and thus the Baja terrain altitude is reduced, VT downstream increases (cf. Figs. 8a,d and Fig. 8g). Likewise, as 
(a) 81L81A

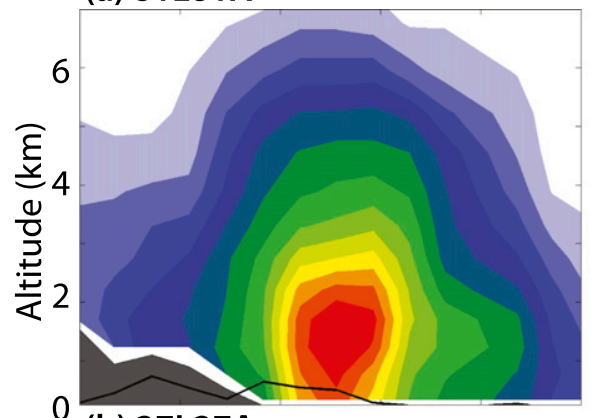

(b) 27L27A

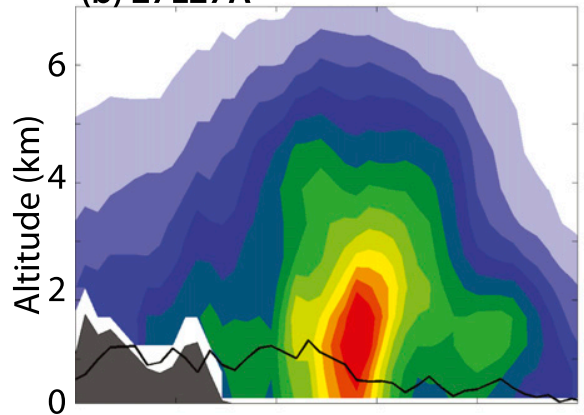

(c) 9 L9A

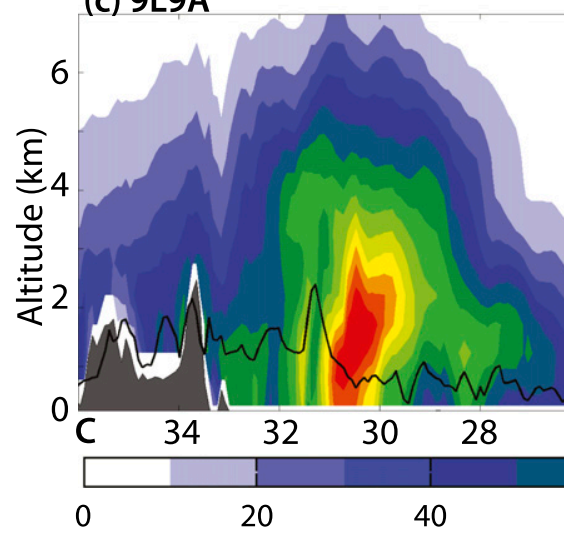

(d) $81 \mathrm{~L} 3 \mathrm{~A}$

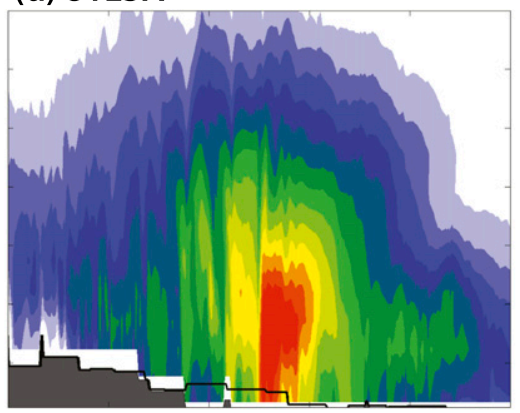

(e) $27 L 3 A$

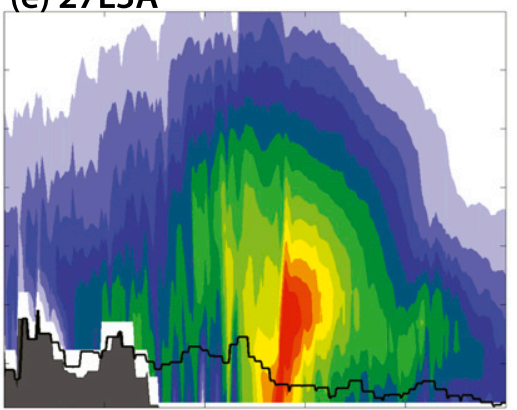

(f) $9 \mathrm{~L} 3 \mathrm{~A}$ (g) CNTL

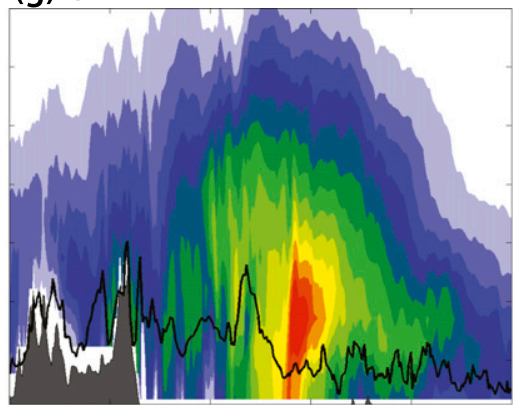

(h) Tall

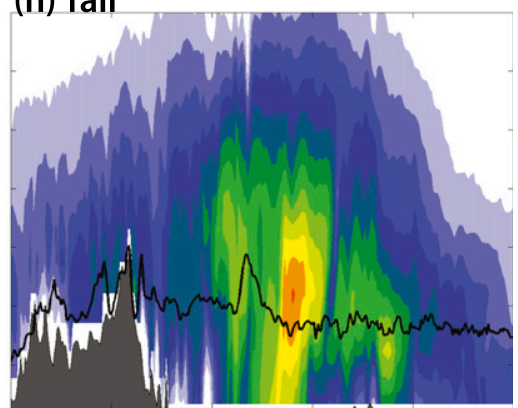

(i) Taller

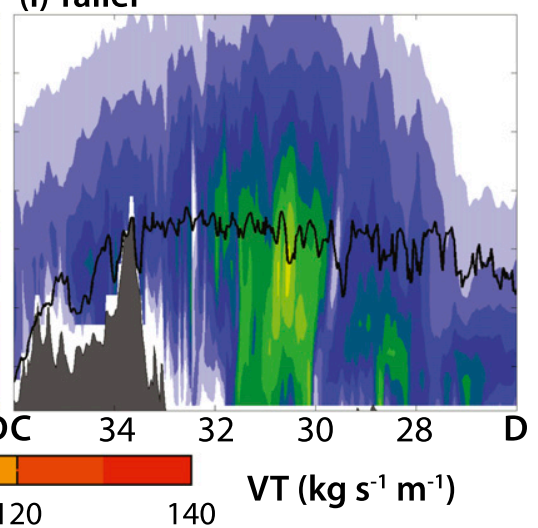

FIG. 8. As in Fig. 7, but for the cross section downstream (i.e., east) of Baja (line C-D on Fig. 6g). The black contour in each panel shows max upstream elevation.

Baja terrain altitude is increased, VT downstream decreases (cf. Fig. 8g and Figs. 8h,i). This reduction in downstream VT is also evident in precipitation amount that fell across Baja (as discussed in section 4a).

Finally, to quantify this effect for all hours of the simulation, we calculate the drying ratio [see section 2c, Eq. (2)] across northern and southern Baja (green and blue boxes in Fig. $6 \mathrm{~g}$, respectively) as a summation of each hour of the simulation. Figure 9 shows average DR for northern and southern Baja for each WRF experiment. An examination of DR confirms the instantaneous values of IVT and VT: as terrain resolution decreases and results in lower terrain heights over Baja California, less water is removed from the AR as it crosses Baja (i.e., DR for CNTL is greater than for the lower-terrain-resolution experiments). In addition, we see that DR is much larger across northern Baja than southern Baja, partially confirming the hypothesis laid out in Part I, that the intense character of the vapor fluxes incident on the Mogollon was partly a consequence of the precise positioning of the AR across the relatively low mountains of southern Baja, rather than across the much higher, northern portion of this range. The impact of coarsened terrain on DR is greater in northern Baja than in southern Baja, likely because the terrain of southern Baja is already quite low and DR are already small in CNTL.

As the terrain height is increased in the Tall and Taller experiments, DR increases. Tall has only slightly raised terrain in northern Baja, and southern Baja was raised to be comparable in height to northern Baja. The DR in 
(a) Northern Baja

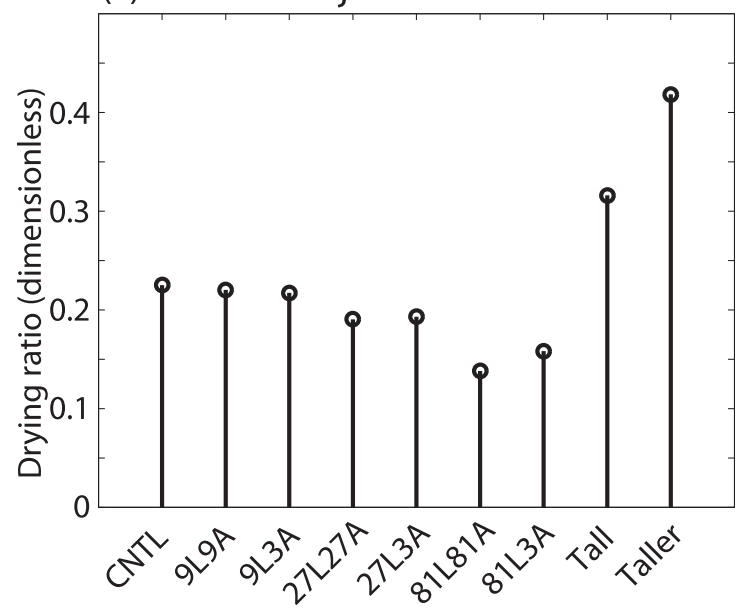

(b) Southern Baja

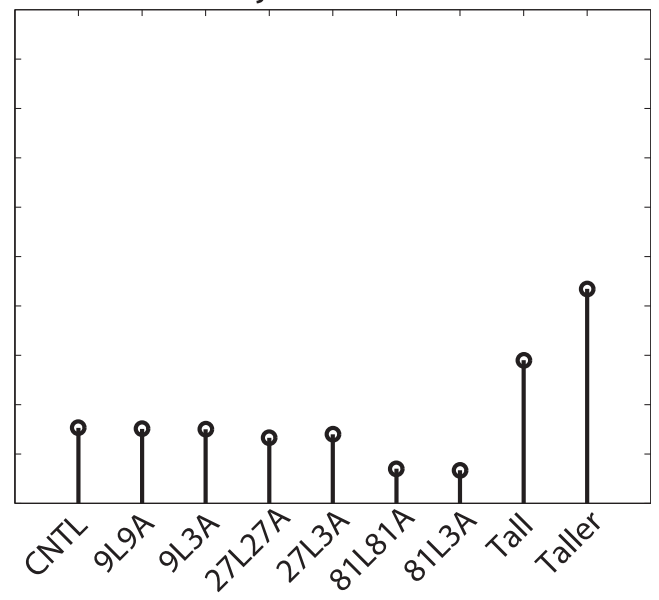

FIG. 9. Drying ratio for entire 48-h simulation (ending at 1800 UTC 22 Jan 2010) for the nine WRF simulations across (a) northern and (b) southern Baja, with areas used in calculations shown in Fig. $6 \mathrm{~g}$.

this experiment increased by about one-third, from 0.23 in CNTL to 0.32 in BajaTall across northern Baja, and has nearly doubled from 0.08 in CNTL to 0.15 in BajaTall across southern Baja. From a DR perspective, this experiment is the closest to answering the question of what would have happened if the AR never traversed southern Baja but rather was more westerly in direction as it impinged on the Mogollon and crossed the higher northern Baja and Southern California terrain instead. Taller has much higher terrain along all of Baja California and subsequently has much larger DR, that is, nearly double the CNTL across northern Baja (CNTL $\mathrm{DR}=0.23$, BajaTaller $\mathrm{DR}=0.42$ ) and nearly triple CNTL across southern Baja (CNTL DR $=0.08$, Baja Taller DR $=0.22$ ).

\section{Sensitivity tests with the LM}

Section 4 investigated the impact of terrain height on IVT across Baja and resultant precipitation and DR in the Mogollon and surrounding regions. In this section, we examine the other dominant term in the upslope model of precipitation - the angle between the direction of the water vapor flux and the local terrain gradientand test the sensitivity of resultant precipitation to that term by artificially rotating the angle of the impinging AR. We focus solely on the Mogollon subdomain (Fig. 10, with geographical context shown in Fig. 1d) and two river basins in the region, the Salt and the Verde (Fig. 10), the former of which was also discussed in Part I.

To rotate the AR impinging on the Mogollon subregion, we employ the linear model, described briefly in section 2d. We apply the LM to the Mogollon subregion only (Fig. 10), using an area southwest of the southwest corner of the Mogollon subregion $\left(31^{\circ}-33^{\circ} \mathrm{N}, 115^{\circ}-\right.$ $\left.113^{\circ} \mathrm{W}\right)$ as "upstream" conditions. The actual LM domain extends approximately $200 \mathrm{~km}$ south and west of the Mogollon subdomain to fully capture the orographic forcing along the south and west edges of the subdomain. The LM solution (i.e., precipitation; $\mathrm{mm} \mathrm{h}^{-1}$ ) was calculated using meteorological variables in this upstream region (layer-averaged temperature, winds, and stability) from CNTL for each hour with nearsurface air in the upstream region that would be saturated at the Mogollon elevation, and then it was summed to obtain total LM precipitation. To calibrate the LM, it was first run for a range of $\tau_{f}$ and $\tau_{c}$ (fallout time and condensation time) values and a limited set of different layer means (averaging from near surface to anywhere between 900 and $700 \mathrm{hPa}$ ) for the meteorological variables. The 48-h LM precipitation from these sensitivity runs was then compared against CNTL precipitation. Averaging from near surface to $800 \mathrm{hPa}, \tau_{f}=1250 \mathrm{~s}$ and $\tau_{c}=900 \mathrm{~s}$ were chosen by minimizing mean-Mogollon and maximum-Mogollon LM precipitation errors (compared against CNTL) in these sensitivity runs.

A comparison of the resultant LM precipitation, hereafter called LM CNTL (Fig. 11b), with that from CNTL (Fig. 11a) reveals that the LM has a similar precipitation distribution to CNTL in this region when applied using meteorological conditions directly upstream. The magnitude and location of LM CNTL local precipitation maxima is close to CNTL across many of the terrain features. However, LM CNTL overestimates the amount of precipitation that falls across many of the terrain features. The LM CNTL precipitation is also a bit too small in regions with light precipitation in CNTL. For these reasons, we will only compare LM results with other 


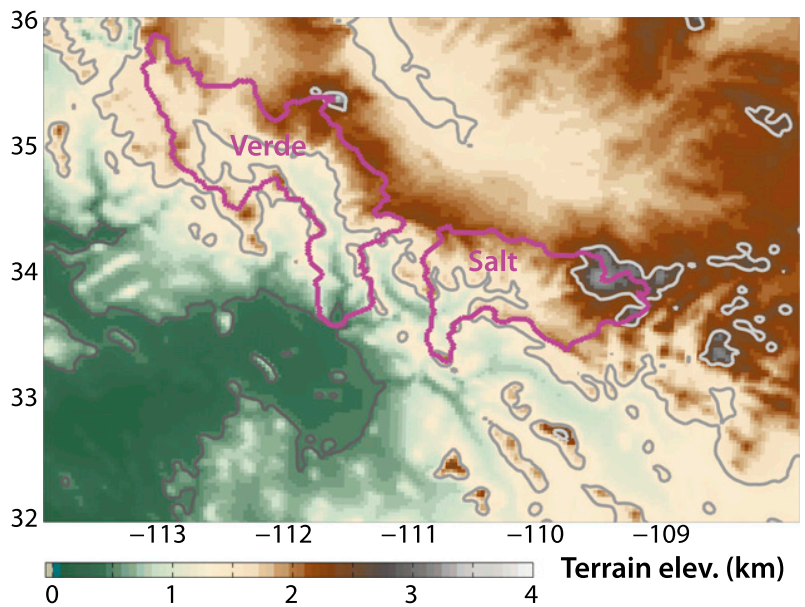

FIG. 10. CNTL terrain elevation in Mogollon subregion (km; color fill), used as terrain for all LM calculations. Grayscale contours show terrain at 500, 1500, and $2500 \mathrm{~m}$ for reference in Figs. 11 and 12. Magenta lines outline the Verde and Salt River basins of Fig. 14.

LM results and not directly with the WRF precipitation amounts shown in section 4.

To adjust the AR "angle" (i.e., the angle as maximum IVT hits topography), we then rotate the LM input winds by angle increments of $10^{\circ}$ ranging from $-40^{\circ}$ (more southerly) to $+40^{\circ}$ (more westerly) from the CNTL direction, while keeping the other input parameters fixed. The heavy black arrow in Fig. 11b shows that the average wind direction during precipitating hours from CNTL is from the south-southwest (from $211^{\circ}$ ), consistent with the snapshot of the AR shown in Fig. $6 \mathrm{~g}$. Figure 12 shows the difference of the resultant LM precipitation from LM CNTL precipitation with winds rotated $-40^{\circ},-20^{\circ},+20^{\circ}$, and $+40^{\circ}$ (Figs. $12 \mathrm{a}-\mathrm{d}$, respectively) away from this control direction (with black arrows showing mean rotated wind direction). As the wind direction shifts, the amount and magnitude of precipitation falling across the terrain shifts accordingly. The largest precipitation changes occur across terrain that shifts from being primarily windward to being within the rain shadow of upstream terrain as the LM input winds are rotated. Also, the region maximum actually shifts from one mountain to another (i.e., region maxima at $34.25^{\circ} \mathrm{N}, 112.5^{\circ} \mathrm{W}$ and $33.5^{\circ} \mathrm{N}, 108.5^{\circ} \mathrm{W}$ when the AR angle is shifted counterclockwise from CNTL; region maxima at $32.5^{\circ} \mathrm{N}, 110.75^{\circ} \mathrm{W}$ and $35^{\circ} \mathrm{N}, 113.75^{\circ} \mathrm{W}$ when AR angle is shifted clockwise from CNTL, not shown) causing dramatic local changes.

To directly compare the sensitivity of Mogollon precipitation to AR angle with its sensitivity to upstream terrain, we next find the LM solution for 3-km terrain using meteorological conditions from the eight terrainsensitivity simulations (not shown). In this case, the (a) CNTL

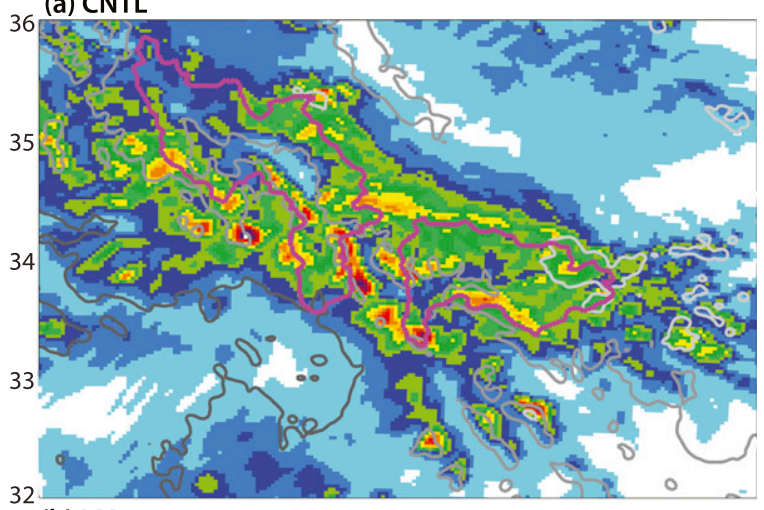

(b) LM

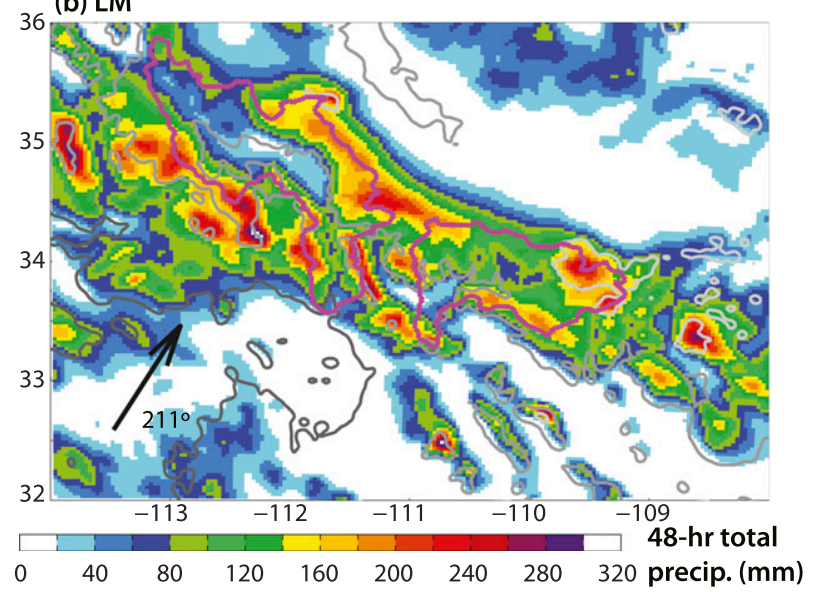

FIG. 11. The 48-h total precipitation ( $\mathrm{mm}$; color fill) ending at 1800 UTC 22 Jan 2010 in (a) CNTL and (b) LM using CNTL winds and temperature in the layer between 1000 and $800 \mathrm{hPa}$ (i.e., LM CNTL). Grayscale contours show terrain at 500,1500, and $2500 \mathrm{~m}$. Heavy black arrow in (b) shows mean wind direction (from $213^{\circ}$ ) computed in the layer between 1000 and $800 \mathrm{hPa}$. Magenta lines outline the Verde and Salt River basins of Fig. 14: west is Verde and east is Salt.

angle of the water vapor flux changes very little from one case to another (e.g., Fig. 6), but instead the magnitude of incoming water vapor flux changes-greater IVT reaches the Mogollon for smaller Baja California DRs (Fig. 9). Because the AR angle is not changing, the distribution of LM precipitation in these solutions changes little, but the magnitude varies dramatically.

We then repeat the Mogollon regionwide mean calculations of section 4 with these LM precipitation amounts (Fig. 13). Focusing on the impact of AR angle (Fig. 13a), we see that the region-mean normalized precipitation is a minimum when the average AR angle is $171^{\circ}$ (rotated $-40^{\circ}$ from $\mathrm{CTNL}$ ), then increases slightly as the $\mathrm{AR}$ angle is rotated just $10^{\circ}$ clockwise, reaching its maximum when the AR is approximately $191^{\circ}$ (rotated $-20^{\circ}$ from CNTL). The change in mean precipitation for every $10^{\circ}$ shift is fairly small, and the largest mean value $(61.6 \mathrm{~mm}$ when 
(a) -40 degrees

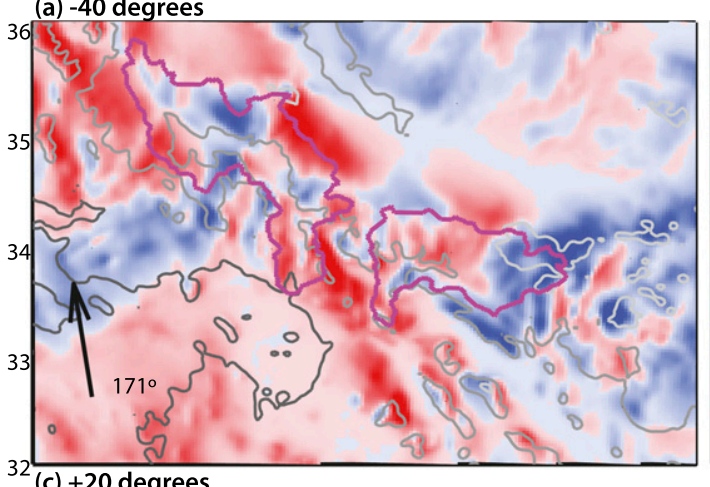

32 (c) +20 degrees

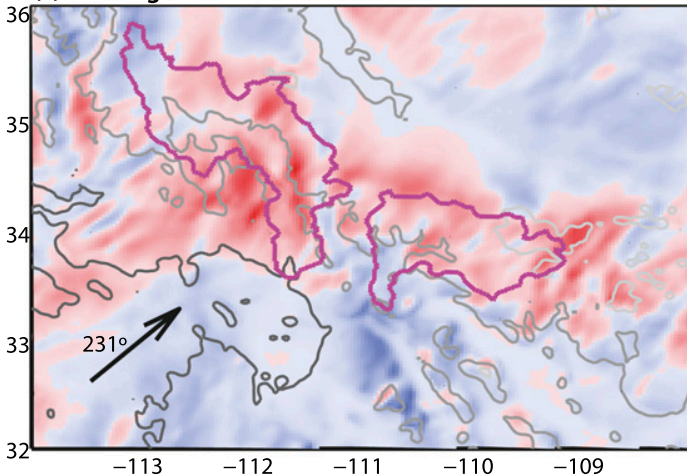

$-60$

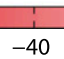

$-20$

0

20 (b) -20 degrees

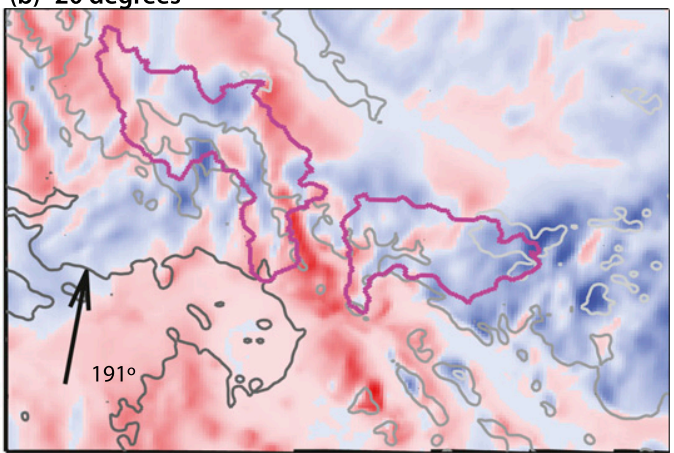

(d) +40 degrees

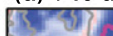

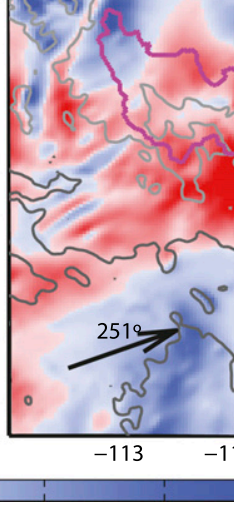

60

80 precip. from control (mm)

FIG. 12. Differences of 48-h total precipitation (mm; color fill) ending at 1800 UTC 22 Jan 2010 between LM and LM CNTL (i.e., LM minus LM CNTL), with 1000-800 hPa wind directions shifted by (a) $-40^{\circ}$, (b) $-20^{\circ}$, (c) $+20^{\circ}$, and (d) $+40^{\circ}$. Grayscale contours show terrain at 500, 1500, and $2500 \mathrm{~m}$. Heavy black arrow shows mean wind direction computed in the layer between 1000 and $800 \mathrm{hPa}$. Magenta lines outline the Verde and Salt River basins of Fig. 14: west is Verde and east is Salt.

AR rotation is $-20^{\circ}$ ) is only $6 \%$ larger than the smallest $\left(57.9 \mathrm{~mm}\right.$ when AR rotation is $\left.-40^{\circ}\right)$. The impact of upstream terrain resolution on Mogollon subregionwide LM precipitation (Fig. 13b) has patterns that are, for the most part, consistent with the drying ratios of Fig. 9: region-mean LM precipitation amounts increase compared to LM CNTL as the Baja terrain height is reduced (i.e., terrain-resolution experiments) and decrease as it gets higher (i.e., in the Tall/Taller experiments), although 9L9A and 27L27A show larger and 81L81A shows smaller Mogollon region-mean LM precipitation than expected from their drying ratio differences. The largest increases from LM CNTL are seen in the $81-\mathrm{km}$ grid spacing simulations: the $81 \mathrm{~L} 81 \mathrm{~A} \mathrm{LM}$ solution has region-mean precipitation $9 \%$ larger than CNTL, while 81L3A LM solution has region-mean precipitation $14 \%$ larger than CNTL. This has important implications for coarse-resolution numerical weather and climate models (and downscalings of those models). A summary of these percentage changes in LM precipitation amounts for the full set of simulations is shown in Table 2.
The LM terrain-resolution sensitivity precipitation amounts (Fig. 13b, first seven bars) are mostly consistent with the drying ratio changes (Figs. 9a,b, first seven bars), whereas the WRF precipitation amounts in the Mogollon region (Fig. 5b, first seven bars) showed no consistent signal. The most obvious reason for this discrepancy is that the reduced terrain grid-spacing simulations (e.g., 81L81A) have lower elevation terrain over the Mogollon region: even if larger IVT is impinging on the region, the coarsened terrain and consequently reduced terrain elevations and gradients may offset the impact this increased IVT has on region mean precipitation. Thus, the comparable Mogollon region-mean precipitation amounts seen across the WRF terrain grid spacing experiments may be the result of a cancellation of errors. The LM results, on the other hand, all have the same 3-km grid spacing terrain driving their precipitation response. This large LM sensitivity, consistent with the drying ratio sensitivity, supports the notion that there may be cancellation of errors leading to the precipitation amounts in Fig. 5b.

If we repeat this analysis for smaller, more hydrologically relevant areas within the Mogollon subregion-in 

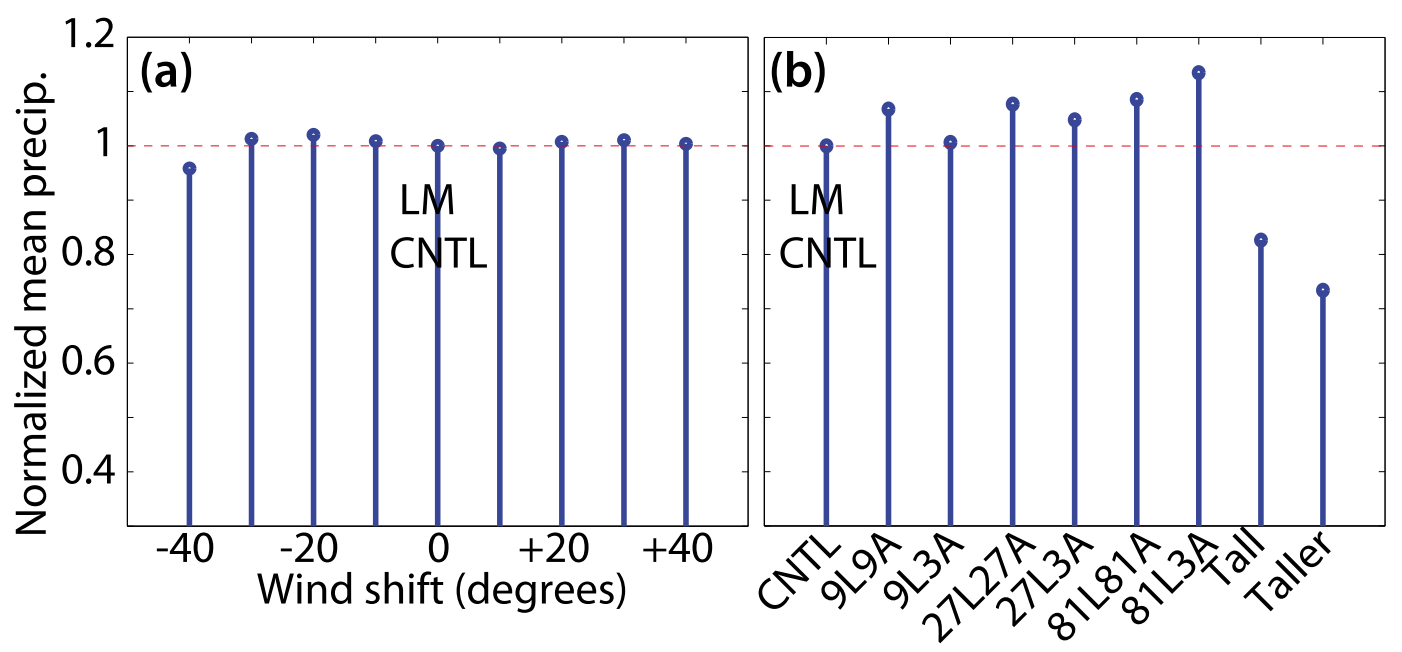

FIG. 13. Mogollon region mean normalized 48-h total precipitation (dimensionless) from LM, normalized by LM CNTL region mean. Variables necessary to run the LM are taken from (a) CNTL, except shifting winds from $-40^{\circ}$ to $+40^{\circ}$, by increments of $10^{\circ}\left(0\right.$ is CNTL winds, which on average are from $211^{\circ}$, computed in the layer between 800 and $1000 \mathrm{hPa}$ ) and (b) the nine terrain-modification WRF simulations ( $3 \mathrm{~km}$ is CNTL). Normalizing factor (i.e., LM CNTL precipitation) is $60 \mathrm{~mm}$.

particular, two river basins that were heavily impacted during this event, the Salt River and the Verde Riverwe see some similarities, but with notable differences (Fig. 14). Both river basins have somewhat reduced basin-mean precipitation sensitivity to changes in upstream terrain height (Figs. 14b,d), particularly to terrain height reductions due to increased grid spacing (see also Table 2). In terms of basin-mean sensitivity to AR angle, the Salt River basin (Fig. 14a) is considerably more sensitive than the entire Mogollon subregion (Fig. 13a) $\left(33 \%\right.$ change from $-20^{\circ}$ to $+40^{\circ}$, Table 2$)$, and the Verde River basin (Fig. 14c) is also more sensitive (33\% change from $-10^{\circ}$ to $+40^{\circ}$, Table 2). Thus, while the regionwide mean precipitation showed rather small sensitivity to AR angle, the more localized and more hydrologically relevant basinwide means are very sensitive to the angle of the incoming water vapor flux.

Because we have used the LM for all of the experiments in this section, we can now directly compare the sensitivity of local precipitation to these two factors: the $\mathrm{AR}$ angle rotation and the upstream terrain height. Regionwide, LM precipitation sensitivity to upstream terrain is generally larger than sensitivity to AR angle. This makes intuitive sense: strength of the water vapor flux acts as the upper/lower limit of the total amount of precipitation that can fall, whereas AR angle determines what percentage of that limit is forced out by lift over the topography. In contrast, AR angle is as or more important than upstream terrain to basinwide precipitation means: physically plausible rotations of AR angle caused changes in basin-mean precipitation as large as $33 \%$, which could have substantial hydrologic impacts. Furthermore, we acknowledge that the sensitivity to upstream terrain height was largely determined by our subjective choice in terrain modification, whereas the AR angle rotations chosen are supported by the climatology of atmospheric rivers making landfall in the southwestern United States (e.g., Neiman et al. 2008b; Rivera et al. 2014). In reality, the AR angle and upstream topography likely interact to determine individual basin susceptibility to ARs with different orientation impacting the interior of the western United States (as in Neiman et al. 2011).

\section{Summary and discussion}

To begin addressing the role of upstream topography in determining water vapor influx to the Intermountain

TABLE 2. Percent change in mean precipitation amounts for the various LM solutions. Values have been calculated as follows: total percent difference $=(\max -\min ) / \min ; \max$ increase from CNTL $=$ $(\max -\mathrm{CNTLp}) / \mathrm{CNTLp}$; and max decrease from CNTL $=(\min -$ CNTLp)/CNTLp, where max is largest region-mean LM precipitation value, min is smallest region-mean LM precipitation value, and CNTLp is region-mean LM precipitation value in LM CNTL.

\begin{tabular}{lrrr}
\hline \hline & $\begin{array}{c}\text { Mogollon } \\
\text { subregion }\end{array}$ & Salt & Verde \\
\hline Total percent difference & $6 \%$ & AR angle \\
Max increase from CNTL & $2 \%$ & $10 \%$ & $33 \%$ \\
Max decrease from CNTL & $-4 \%$ & $-18 \%$ & $-24 \%$ \\
& \multicolumn{3}{c}{ Upstream terrain } \\
Total percent difference & $55 \%$ & $22 \%$ & $44 \%$ \\
Max increase from CNTL & $14 \%$ & $6 \%$ & $7 \%$ \\
Max decrease from CNTL & $-27 \%$ & $-13 \%$ & $-26 \%$ \\
\hline
\end{tabular}




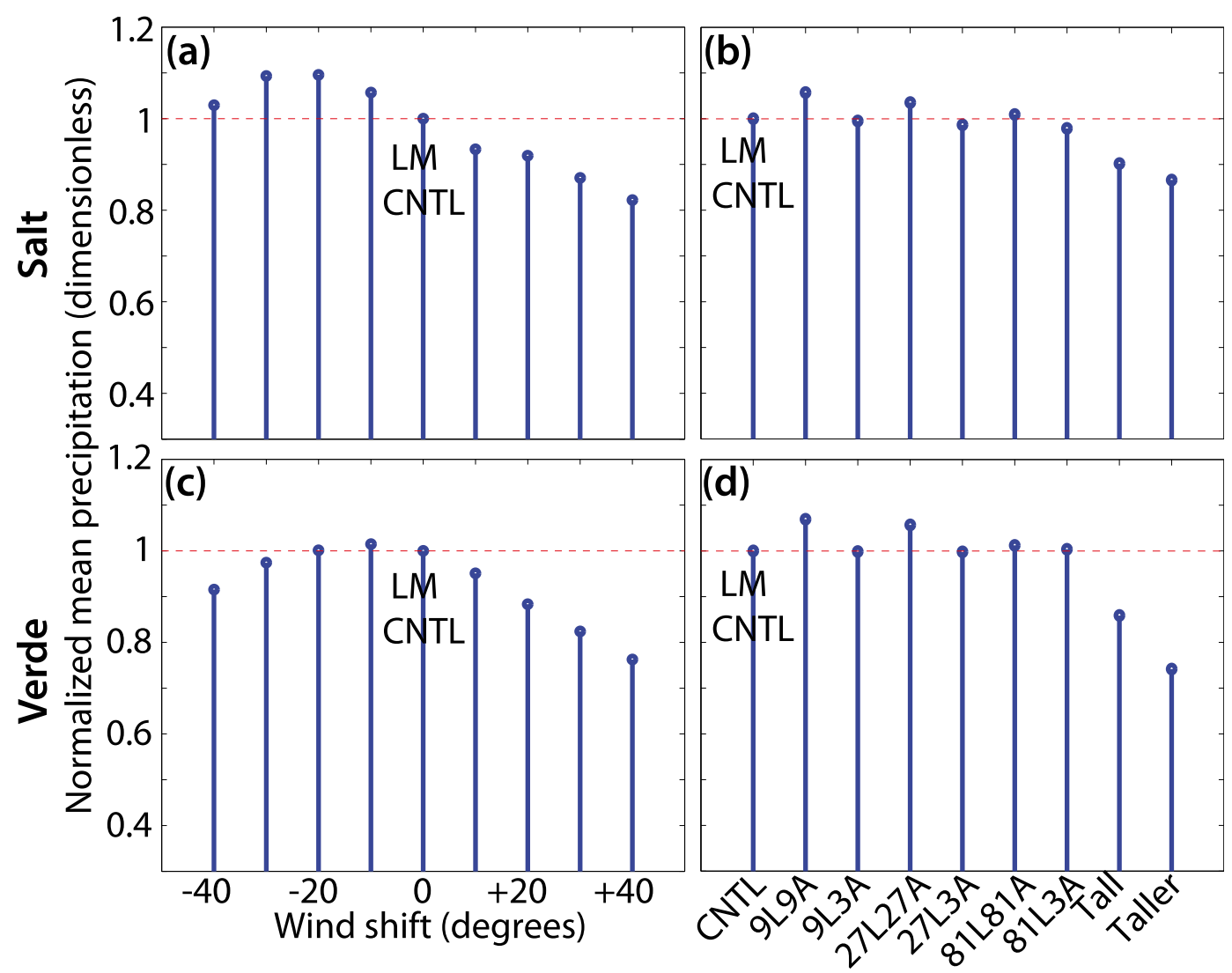

FIG. 14. As in Fig. 13, but for the (a),(b) Salt River and (c),(d) Verde River basins. Normalizing factors (i.e., LM CNTL precipitation areal means) are (a),(b) 127.7 and (c),(d) $104.6 \mathrm{~mm}$.

West, this manuscript presents the second part of a twopart case study of an atmospheric river (AR) event that caused extreme precipitation in Arizona in January 2010. To assess the sensitivity of interior precipitation amounts and water vapor flux to model grid resolution and height of Baja California terrain, we perform a set of sensitivity experiments with the WRF Model, using a 3-km WRF simulation as the CNTL. Sensitivity experiments were performed with WRF: 1) three simulations where model grid spacing decreases sequentially from 81 to 27 to $9 \mathrm{~km}, 2$ ) three simulations where model terrain grid spacing decreases sequentially from 81 to 27 to $9 \mathrm{~km}$ while the atmospheric resolution remains fixed at $3 \mathrm{~km}$, and 3) two simulations where upstream (i.e., Baja California) terrain is increased. CNTL IVT is compared to IVT from the CFSR, and WRF bulk IWV flux is compared to bulk IWV flux calculated from GPS met and wind profilers. In addition, CNTL precipitation is compared against stage IV quantitative precipitation estimation (QPE) and gauges. These model variables agree reasonably well with observations, justifying our use of the CNTL simulation as a baseline for further sensitivity experiments.
The WRF experiments show that, as the terrain of Baja California is raised, larger amounts of precipitation fall across Baja, and smaller amounts fall across Arizona downstream of Baja; as terrain grid spacing is coarsened, less precipitation falls across Baja, but precipitation amounts across Arizona change only minimally. This precipitation relationship is then investigated from a VT perspective: as terrain height in Baja increases, the terrain removes more water vapor and water vapor transport (VT) generally decreases downstream of Baja. Interestingly, the simulations with increased Baja terrain exhibit somewhat elevated VT maxima owing to accelerated winds over their higher terrain. The VT relationship is then quantified by calculating the drying ratio of Baja California for the WRF simulations. The drying ratio across Baja increases when its terrain height is increased and decreases as terrain grid spacing coarsens (i.e., as the Baja terrain becomes lower). Supporting a hypothesis presented in Part I, the drying ratio of northern Baja is much larger than that of southern Baja.

A linear model (LM) for orographic precipitation is used to address the importance of 1 ) the angle of the AR 
relative to the topography it impinges on and 2) the upstream topography to precipitation in the Mogollon region. The actual incidence angle of the AR $\left(211^{\circ}\right)$ is close to the optimum angle for large region-mean precipitation. Changes in region-mean precipitation amounts of $6 \%$ are seen within the range of physically plausible AR angles tested (i.e., from $-40^{\circ}$ to $+40^{\circ}$ of that observed). However, changes in basin-mean precipitation amounts for the same range of AR angles are much larger (up to $33 \%$ ), driving home the importance of representing orographic precipitation distribution at high resolution to resolve basin scales. To quantitatively compare this sensitivity with precipitation sensitivity to the Baja terrain height, the LM is then applied using meteorological parameters (i.e., LM input data) from the terrain-sensitivity WRF simulations and CNTL Arizona terrain. Regionwide, larger precipitation sensitivity is seen with the terrain-modification experiments (due to modification of incoming IVT magnitudes) than with AR angle modification (Table 2), although this depends strongly on the rather subjective modifications made to upstream terrain. Within individual basins, AR angle plays a more dominant role determining mean precipitation amounts.

In reality, both upstream terrain (determined by an $\mathrm{AR}$ trajectory) and AR angle relative to the local topography interact to determine resultant precipitation. The specific situation for the Mogollon subregion and Verde River basin is laid out schematically in Fig. 15. The impact of ARs making landfall in Arizona that are more westerly than CNTL are limited by passage across the high terrain of northern Baja because of its larger drying ratio than for southern Baja. The local orographic precipitation response to the AR angle incident on the topography in both the Verde and Salt River basins is largest for angles ranging from $\sim 181^{\circ}$ to $\sim 211^{\circ}$ (Fig. 14), with the angle of greatest response dependent on the basin itself. The AR of 20-22 January 2010 caused widespread large precipitation amounts in the Mogollon subregion because it fell within the range of angles where AR trajectory and local terrain effects both favor a large precipitation response, although, had it been somewhat more southerly, the local precipitation in the Salt River basin would have likely been even more extreme.

While upstream terrain modification is largely an artificial experiment, it allows for a clear hypothesis test, leading to better understanding of the sensitivity of inland-penetrating ARs and resulting precipitation to terrain grid spacing. This test has highly practical implications for global climate models, global operational forecast models, and reanalysis datasets that regularly use grid spacing much coarser than $10 \mathrm{~km}$. In particular,

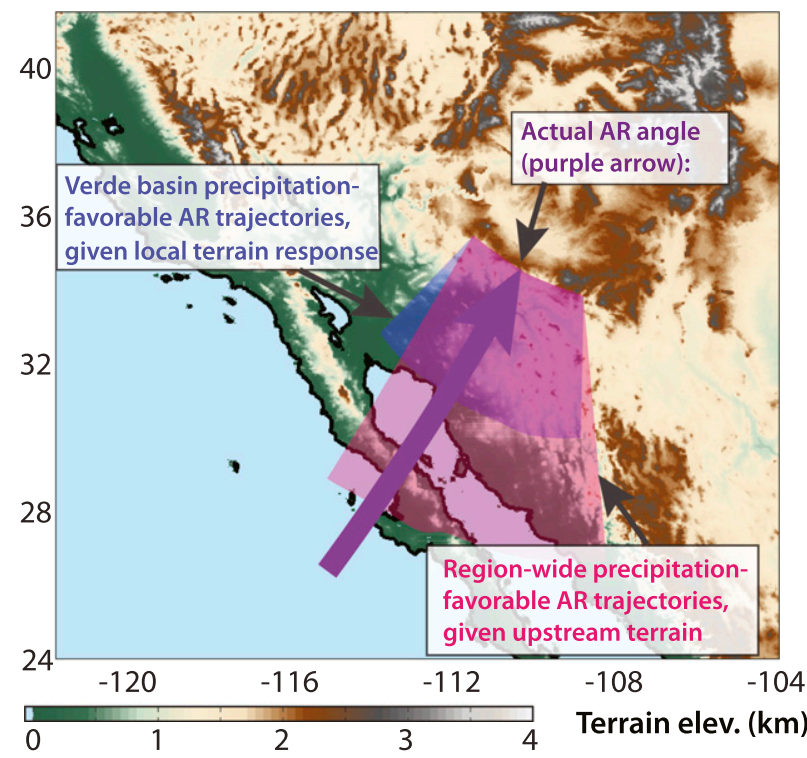

FIG. 15. Conceptual schematic (km; with color-fill terrain shading) of two competing controls on orographic precipitation amounts investigated in this manuscript. Pink swath shows range of AR angles where large precipitation amounts are not limited by upstream topography. Blue swath shows range of AR angles favored by Verde basin local topography for large precipitation amounts. The overlap of these two swaths shows range of angles for which both favor large precipitation amounts. Purple arrow shows average angle of winds in AR from CNTL.

the 81L81A simulation (which is comparable resolution to current reanalysis and climate models) has far too much water vapor crossing Baja California, evidenced by its drying ratio being $63 \%$ of the CNTL drying ratio. While the precipitation response to this is compensated for by coarsened Arizona terrain in the 81L81A experiment, the LM solution shows large precipitation amounts for the 81L81A simulation. Subsequently, while downscaling coarse-resolution atmospheric data (e.g., reanalysis datasets or global climate models) can address the representation of finescale local processes, it does not account for processes outside the domain, in this case the impact of upstream topography on moisture transport. Downscaled simulations based on coarse-resolution products could be very sensitive to the incoming IVT amounts (e.g., Hahn and Mass 2009), and large overestimates of IVT penetrating the Intermountain West in coarse-resolution numerical products (e.g., McAfee et al. 2011) could be a source of error in simulations and reanalysis that employ coarse-resolution models.

Acknowledgments. This research is supported by the U.S. Bureau of Reclamation. Thanks to Chengmin Hsu for the mapping of the Salt and Verde River basins. We also thank three anonymous reviewers whose comments greatly improved the manuscript. 


\section{REFERENCES}

Baldwin, M. E., and K. E. Mitchell, 1998: Progress on the NCEP hourly multi-sensor U.S. precipitation analysis for operations and GCIP research. Preprints, Second Symp. on Integrated Observing Systems, Phoenix, AZ, Amer. Meteor. Soc., 10-11.

Barstad, I., and F. Schüller, 2011: An extension of Smith's linear theory of orographic precipitation: Introduction of vertical layers. J. Atmos. Sci., 68, 2695-2709, doi:10.1175/JAS-D-10-05016.1.

Chen, F., and J. Dudhia, 2001: Coupling an advanced land surfacehydrology model with the Penn State-NCAR MM5 modeling system. Part I: Model implementation and sensitivity. Mon. Wea. Rev., 129,569-585, doi:10.1175/1520-0493(2001)129<0569: CAALSH $>2.0 . \mathrm{CO} ; 2$.

Dettinger, M., 2011: Climate change, atmospheric rivers, and floods in California-A multimodel analysis of storm frequency and magnitude changes. J. Amer. Water Resour. Assoc., 47, 514523, doi:10.1111/j.1752-1688.2011.00546.x.

— , K. Redmond, and D. Cayan, 2004: Winter orographic precipitation ratios in the Sierra Nevada-Large-scale atmospheric circulations and hydrologic consequences. J. Hydrometeor., 5, 1102-1116, doi:10.1175/JHM-390.1.

_ , and Coauthors, 2012: Design and quantification of an extreme winter storm scenario for emergency preparedness and planning exercises in California. Nat. Hazards, 60, 1085-1111, doi:10.1007/s11069-011-9894-5.

Dudhia, J., 1989: Numerical study of convection observed during the winter monsoon experiment using a mesoscale twodimensional model. J. Atmos. Sci., 46, 3077-3107, doi:10.1175/ 1520-0469(1989)046<3077:NSOCOD >2.0.CO;2.

Hahn, R. S., and C. F. Mass, 2009: The impact of positive-definite moisture advection and low-level moisture flux bias over orography. Mon. Wea. Rev., 137, 3055-3071, doi:10.1175/ 2009MWR2873.1.

Hong, S.-Y., Y. Noh, and J. Dudhia, 2006: A new vertical diffusion package with an explicit treatment of entrainment processes. Mon. Wea. Rev., 134, 2318-2341, doi:10.1175/MWR3199.1.

Hughes, M., A. Hall, and R. Fovell, 2009: Blocking in areas of complex topography, and its influence on rainfall distribution. J. Atmos. Sci., 66, 508-518, doi:10.1175/2008JAS2689.1.

Iacono, M. J., J. S. Delamere, E. J. Mlawer, M. W. Shephard, S. A. Clough, and W. D. Collins, 2008: Radiative forcing by longlived greenhouse gases: Calculations with the AER radiative transfer models. J. Geophys. Res., 113, D13103, doi:10.1029/ 2008JD009944.

Kain, J. S., 2004: The Kain-Fritsch convective parameterization: An update. J. Appl. Meteor., 43, 170-181, doi:10.1175/ 1520-0450(2004)043<0170:TKCPAU > 2.0.CO;2.

Kirshbaum, D. J., and R. B. Smith, 2008: Temperature and moiststability effects on midlatitude orographic precipitation. Quart. J. Roy. Meteor. Soc., 134, 1183-1199, doi:10.1002/qj.274.

Leung, L. R., and Y. Qian, 2009: Atmospheric rivers induced heavy precipitation and flooding in the western U.S. simulated by the WRF regional climate model. Geophys. Res. Lett., 36, L03820, doi:10.1029/2008GL036445.

Lin, Y., and K. E. Mitchell, 2005: The NCEP Stage II/IV hourly precipitation analyses: Development and applications. 19th Conf. on Hydrology, San Diego, CA, Amer. Meteor. Soc., 1.2. [Available online at https://ams.confex.com/ams/pdfpapers/ 83847.pdf.]

Lundquist, J. D., J. R. Minder, P. J. Neiman, and E. Sukovich, 2010: Relationships between barrier jet heights, orographic precipitation gradients, and streamflow in the Northern Sierra Nevada. J. Hydrometeor., 11, 1141-1156, doi:10.1175/2010JHM1264.1.
McAfee, S. A., J. L. Russell, and P. J. Goodman, 2011: Evaluating IPCC AR4 cool-season precipitation simulations and projections for impacts assessment over North America. Climate Dyn., 37, 2271-2287, doi:10.1007/s00382-011-1136-8.

Neiman, P. J., F. M. Ralph, G. A. Wick, Y.-H. Kuo, T.-K. Wee, Z. Ma, G. H. Taylor, and M. D. Dettinger, 2008a: Diagnosis of an intense atmospheric river impacting the Pacific Northwest: Storm summary and offshore vertical structure observed with COSMIC satellite retrievals. Mon. Wea. Rev., 136, 4398-4420, doi:10.1175/2008MWR2550.1.

,,--- J. D. Lundquist, and M. D. Dettinger, 2008b: Meteorological characteristics and overland precipitation impacts of atmospheric rivers affecting the West Coast of North America based on eight years of SSM/I satellite observations. J. Hydrometeor., 9, 22-47, doi:10.1175/2007JHM855.1.

— A. B. White, F. M. Ralph, D. J. Gottas, and S. I. Gutman, 2009: A water vapour flux tool for precipitation forecasting. Proc. Inst. Civ. Eng.: Water Manage., 162, 83-94, doi:10.1680/ wama.2009.162.2.83.

, L. J. Schick, F. M. Ralph, M. Hughes, and G. A. Wick, 2011: Flooding in western Washington: The connection to atmospheric rivers. J. Hydrometeor., 12, 1337-1358, doi:10.1175/ 2011JHM1358.1.

_ F. M. Ralph, B. J. Moore, M. Hughes, K. M. Mahoney, J. M. Cordeira, and M. D. Dettinger, 2013: The landfall and inland penetration of a flood-producing atmospheric river in Arizona. Part I: Observed synoptic-scale, orographic, and hydrometeorological characteristics. J. Hydrometeor., 14, 460-484, doi:10.1175/JHM-D-12-0101.1.

Ralph, F. M., P. J. Neiman, D. E. Kingsmill, P. O. G. Persson, A. B. White, E. T. Strem, E. D. Andrews, and R. C. Antweiler, 2003: The impact of a prominent rain shadow on flooding in California's Santa Cruz Mountains: A CALJET case study and sensitivity to the ENSO cycle. J. Hydrometeor., 4, 1243-1264, doi:10.1175/1525-7541(2003)004<1243:TIOAPR > 2.0.CO;2.

, — - and R. Rotunno, 2005: Dropsonde observations in low-level jets over the northeastern Pacific Ocean from CALJET-1998 and PACJET-2001: Mean vertical-profile and atmospheric-river characteristics. Mon. Wea. Rev., 133, 889-910, doi:10.1175/MWR2896.1.

,-- G. A. Wick, S. I. Gutman, M. D. Dettinger, D. R. Cayan, and A. B. White, 2006: Flooding on California's Russian River: Role of atmospheric rivers. Geophys. Res. Lett., 33, L13801, doi:10.1029/2006GL026689.

Rivera, E., F. Dominguez, and C. Castro, 2014: Atmospheric rivers and extreme cool season precipitation events in the Verde River basin of Arizona. J. Hydrometeor., 15, 813-829, doi:10.1175/JHM-D-12-0189.1.

Roe, G. H., 2005: Orographic precipitation. Annu. Rev. Earth Planet. Sci., 33, 645-671, doi:10.1146/annurev.earth.33.092203.122541.

Rotunno, R., and R. Ferretti, 2001: Mechanisms of intense Alpine rainfall. J. Atmos. Sci., 58, 1732-1749, doi:10.1175/ 1520-0469(2001)058<1732:MOIAR $>2.0$. CO; 2 .

Rutz, J. J., and W. J. Steenburgh, 2012: Quantifying the role of atmospheric rivers in the interior western United States. Atmos. Sci. Lett., 13, 257-261, doi:10.1002/asl.392.

- - — , and F. M. Ralph, 2014: Climatological characteristics of atmospheric rivers and their inland penetration over the western United States. Mon. Wea. Rev., 142, 905-921, doi:10.1175/ MWR-D-13-00168.1.

Saha, S., and Coauthors, 2010: The NCEP Climate Forecast System Reanalysis. Bull. Amer. Meteor. Soc., 91, 1015-1057, doi:10.1175/ 2010BAMS3001.1. 
Skamarock, W. C., and Coauthors, 2008: A description of the Advanced Research WRF version 3. NCAR Tech. Note NCAR/ TN-475+STR, 113 pp., doi:10.5065/D68S4MVH.

Smith, B. L., S. E. Yuter, P. J. Neiman, and D. E. Kingsmill, 2010: Water vapor fluxes and orographic precipitation over northern California associated with a landfalling atmospheric river. Mon. Wea. Rev., 138, 74-100, doi:10.1175/ 2009MWR2939.1.

Smith, R. B., 1979: The influence of mountains on the atmosphere. Advances in Geophysics, Vol. 21, Academic Press, 87-230, doi:10.1016/S0065-2687(08)60262-9.

_ 2003: A linear upslope-time-delay model for orographic precipitation. J. Hydrol., 282, 2-9, doi:10.1016/S0022-1694(03)00248-8.

—_, 2006: Progress on the theory of orographic precipitation. Spec. Pap. Geol. Soc. Amer., 398, 1-16, doi:10.1130/ 2006.2398(01).

- and I. Barstad, 2004: A linear theory of orographic precipitation. J. Atmos. Sci., 61, 1377-1391, doi:10.1175/ 1520-0469(2004)061<1377:ALTOOP>2.0.CO;2.

, and J. P. Evans, 2007: Orographic precipitation and water vapor fractionation over the southern Andes. J. Hydrometeor., 8, 3-19, doi:10.1175/JHM555.1.
, I. Barstad, and L. Bonneau, 2005: Orographic precipitation and Oregon's climate transition. J. Atmos. Sci., 62, 177-191, doi:10.1175/JAS-3376.1.

Thompson, G., P. R. Field, R. M. Rasmussen, and W. D. Hall, 2008: Explicit forecasts of winter precipitation using an improved bulk microphysics scheme. Part II: Implementation of a new snow parameterization. Mon. Wea. Rev., 136, 5095-5115, doi:10.1175/2008MWR2387.1.

White, A. B., F. M. Ralph, J. R. Jordan, C. W. King, D. J. Gottas, P. J. Neiman, L. Bianco, and D. E. White, 2007: Expanding the NOAA profiler network: Technology evaluation and new applications for the coastal environment. Seventh Conf. on Coastal Atmospheric and Oceanic Prediction and Processes, San Diego, CA, Amer. Meteor. Soc., 8.6. [Available online at https://ams.confex.com/ams/pdfpapers/127228.pdf.]

Zhang, J., Y. Qi, D. Kingsmill, and K. Howard, 2012: Radar-based quantitative precipitation estimation for the cool season in complex terrain: Case studies from the NOAA Hydrometeorology Testbed. J. Hydrometeor., 13, 1836-1854, doi:10.1175/JHM-D-11-0145.1.

Zhu, Y., and R. E. Newell, 1998: A proposed algorithm for moisture fluxes from atmospheric rivers. Mon. Wea. Rev., 126, 725-735, doi:10.1175/1520-0493(1998)126<0725:APAFMF>2.0.CO;2. 